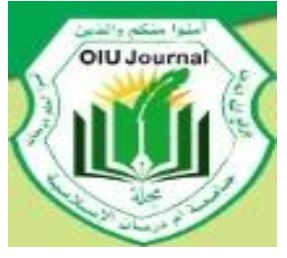

2015; 11(2):282-312
Omdurman Islamic University Journal(OIUJ)

بجلة جامعة أم درمان الاسلامية

https://journal.oiu.edu.sd/index.php/oiuj

https://doi.org/10.52981/oiuj.v11i2.1713

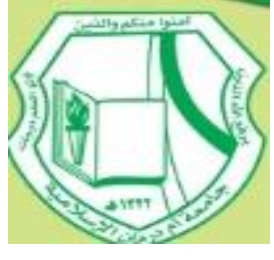

ISSN: 5361-858

\title{
نموذج استراتيجي للخصخصة الناجحة
}

\section{د. عبد الله الطيب محمد العربي"}

\section{مُستخلص:}

تبرز أهمية هذا البحث من أنه محاولة لملء الفراغ الذب تُعاني منه غالبية الدول النامية وخاصة جمهورية السودان،نتيجة لعدم وجود إستراتيجية تهتدي بها لتحقيق الخصخصة الناجحة، و إنه

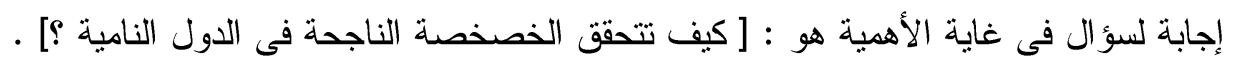
وقد هدف البحث إلى إلقاء الضوء على مخاطر التطبيقات الخاطئة للخصخصة في الدول

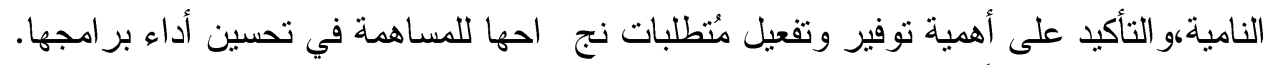

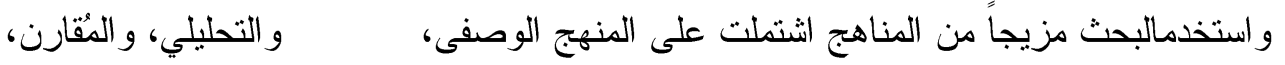
و والاستتباطي، و الاستقر ائي .

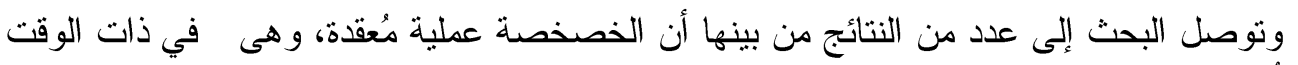

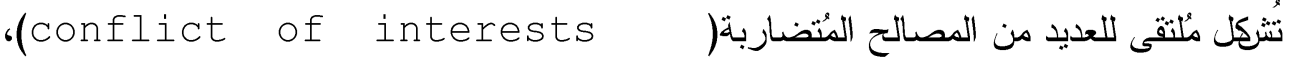
كم أنالتطبيقات الخاطئة للخصخصة، لتوظو اهر الفساد و المحسوبية التي صاحبت تلكالتطبيقات قد ساعدت على بروز كثير من المُشكلات الاقتصاديةو الاجتماعية .

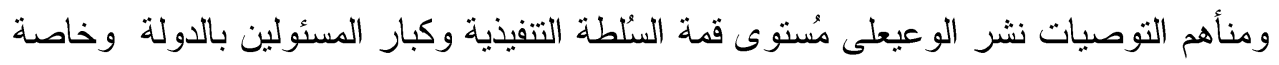
مُتخذي القر ار ات المُتعلقة بالخصخصة حول المخاطر التي يُمكن أن تتجُم عن الأخطاء في لئي

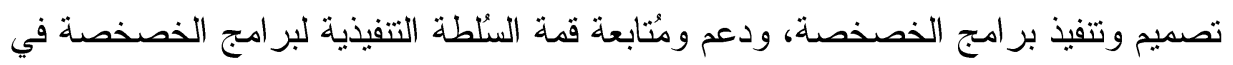

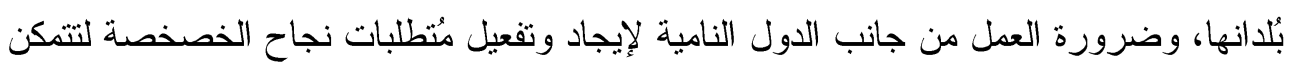
من تحقيق المزيد من النتائج الإيجابية . ملهن 


\section{د. عبد الله الطيبنموذج استراتيجي للخصغصة الناجحةص:312:}

\section{ABSTRACT:}

The importance of this research arises from its attempt to correct the weaknesses encountered by most developing countries namely The Republic of Sudan due to the absence of strategies that set leading guidelines for successful privatization processes. This research provides a full answer to a crucial question[ How can successful privatization be achievedin developing countries? ]The objective of this research extends to help privatization decision makers to avoid problems arising from application, as well as enhancing privatization programs by offering strong support to achieve their targets. Themethodology adopted by this research is a combination of many research methodologies such as descriptive, analytical, comparative, inductive and deductive approaches. The research findings are many، namely privatization is a complicated phenomenon, andat the same time, represents a junction where interests of conflicting parties meet corruption \& cronyism that may accompany the execution of privatization has aggravated more economic \& social problems. The recommendations proposed by this research include, more attention should be paid to promote awareness (among the top executive authorities, senior government staff \& privatization process executors) to the risks associated with improper designing \& incorrect implementation of privatization .Support and follow-up from the top government authorities to privatization programs will help minimize the problems that might hinder application. Governments to provide their countries with thenecessary prerequisites for successful privatization should adopt proper actions 
بجلةجامعقأمدرمان الإسلامية (العدد السابع والعشرونوالثاني عشر الكترونيا) العام 1437هـ 2015م

مُقديمة :

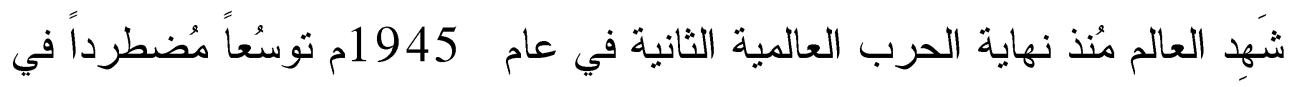

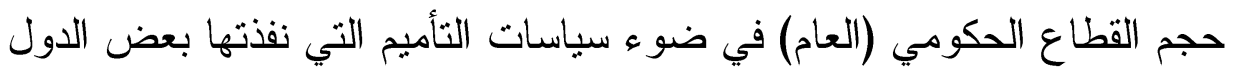

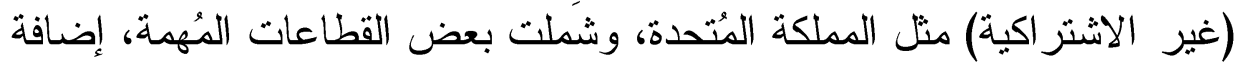

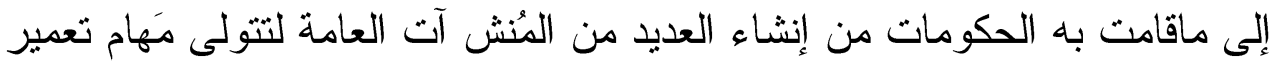

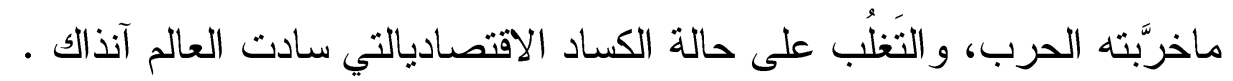

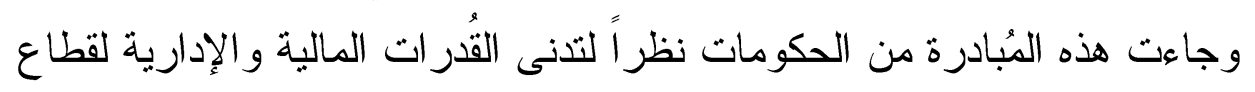

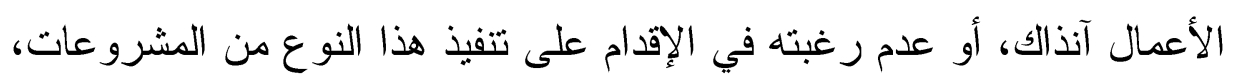

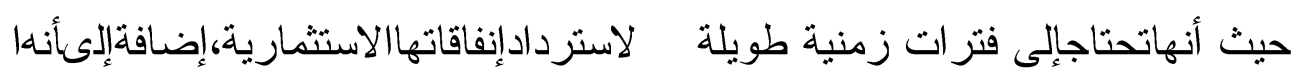
تحَتِْل بعض أو جها المَخاطر.

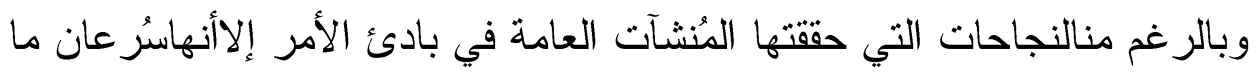

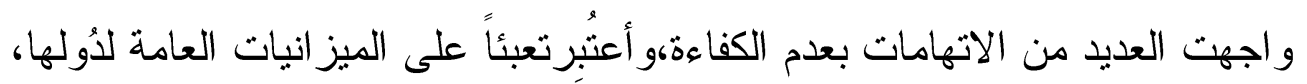

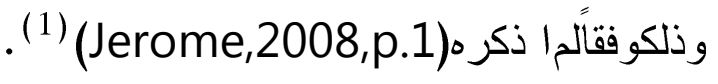

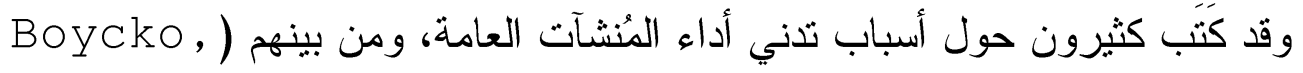

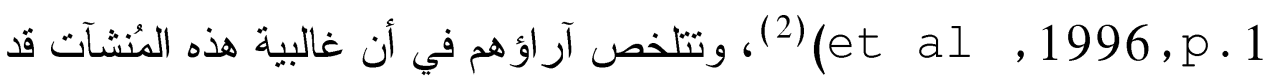

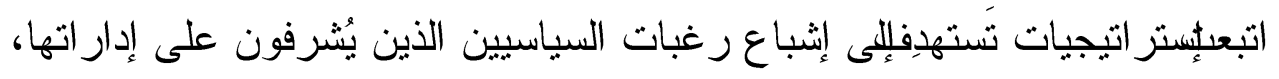
حيث أصبحت تستجيب إلى توظيف عمالة أكثر من حاجة العمل، وتقوم بتحديد التهايد أسعار للسلع و الذمات التي تنتجُها لاتتاسب مع تَكلفتها الفعلية. وخلال العقدين الأخيرين من القرن الميلادي المنصرم وجدت تطبيقات الخصخصة

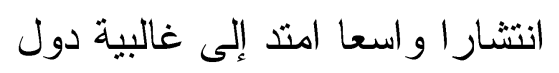

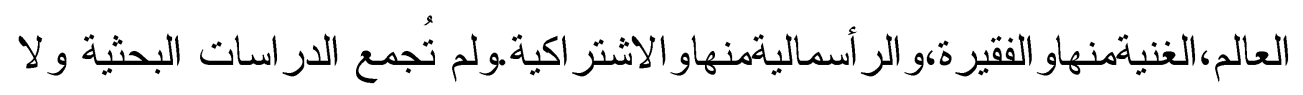

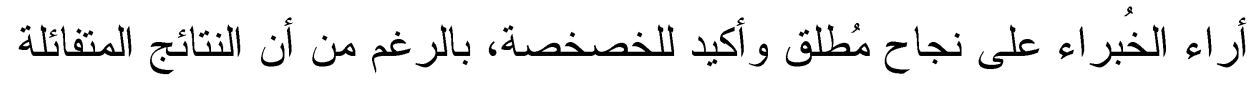




\section{د. عبد الله الطيبنموذج استراتيجي للخصغصة الناجحةص:312:}

لهذه الدراسات تميل إلى تفضيل أداء إدارة القطاع الخاص على أداء الإدارة

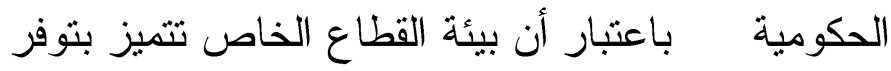

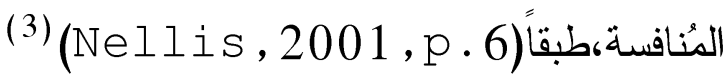

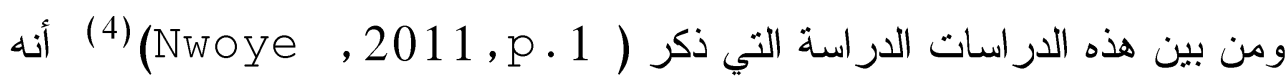

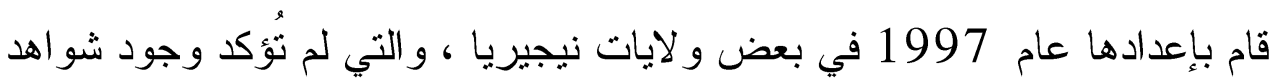

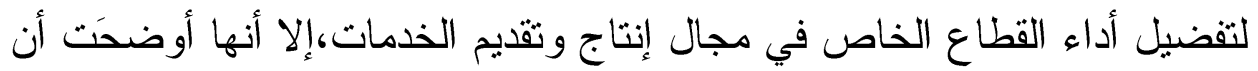

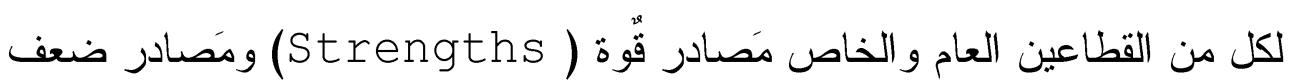
- (Weaknesses) و هذا ماجعل الباحث يقف مُؤيداً لآر ائه الصَريحة التي ذكرفيها ( أنه من الصعوبة وصف الخصخصة بأنها وسيلة جيدة للإصلاح الاقتصادي للدول، أو وسيلة سيئة،

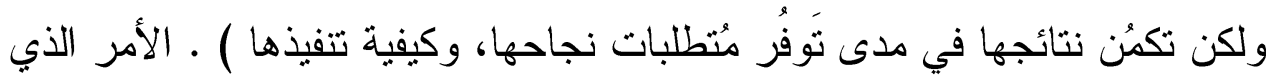

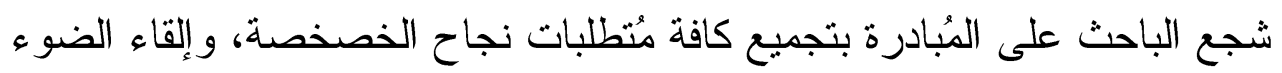

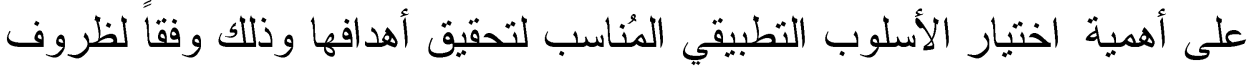
وأوضاع البلد المعني من ناحية، وحالة المُنشأة الخاضعة للخصخصة من ناحية ثانية، ووضع المحاذير و التحوطات الأزمة للخروج بنموذج استر اتيجي للخصخصة

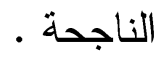




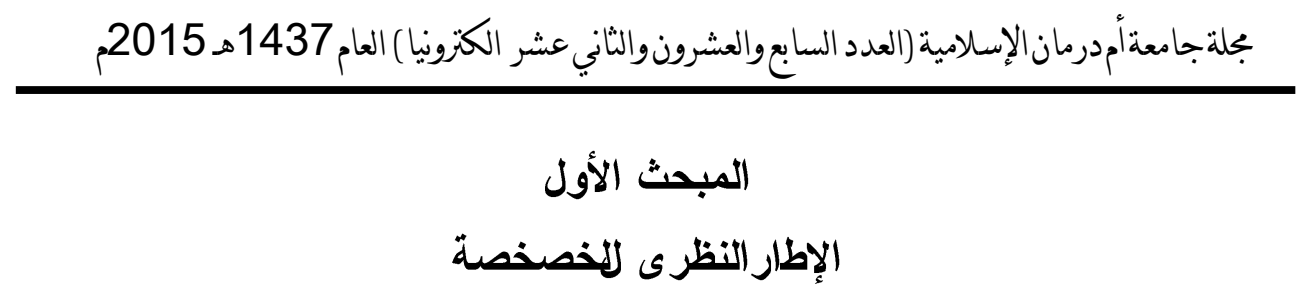

1-1 1 تعريف الخصخصة:

وردت للخصخصة العديد من التعريفات (Definitions) ) فقد عرفها (5oung, 1991, p. 50) التعريف الضيق (Narrow Definition) :

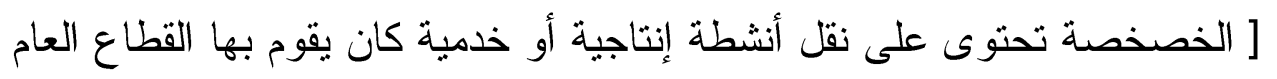

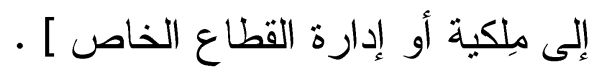

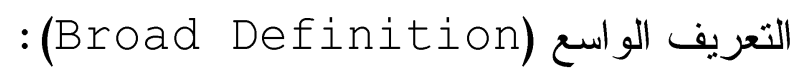
[ الخصخصة هيعملية يتم بمقتضاها تقليص دور الدولة في مُمارسة النشاط

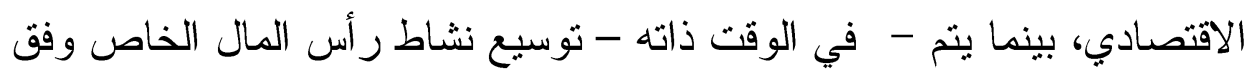

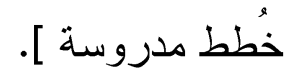

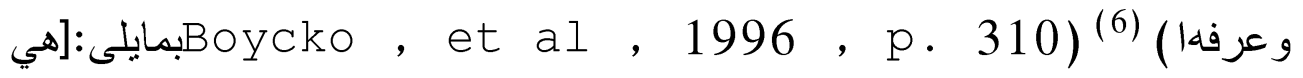
عملية تكاملية تشتمل عائاعادة ترتيب سئلة الصلاحيات فى توظيف العمالة

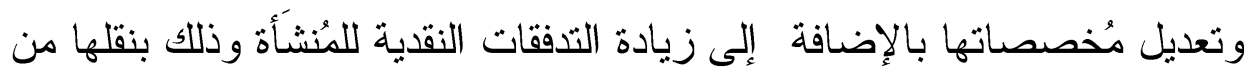

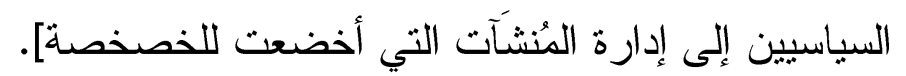

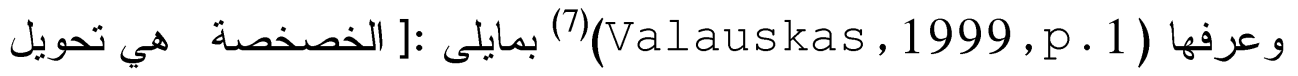

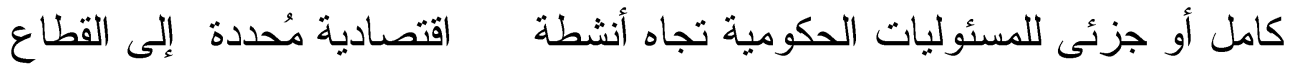

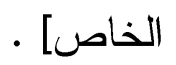

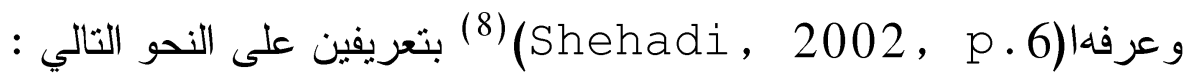
التعريف الضيق (Narrow Definition) : 


\section{د. عبد الله الطيبنموذج استراتيجي للخصخصة الناجحةص:312_ي}

[ إن الخصخصة هي نقل الملكية أو نقل حق التحكم Control

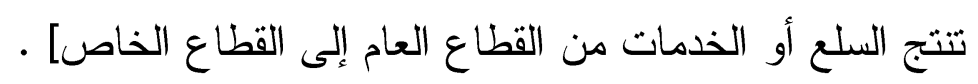

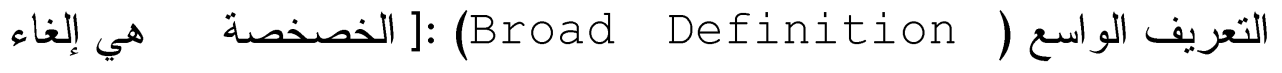
القيود التي تقف عائقاً أمام القطاع الخاص للقيام بمهام التزويد (Abolition)

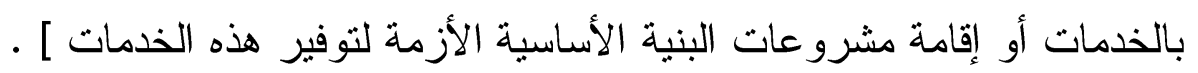

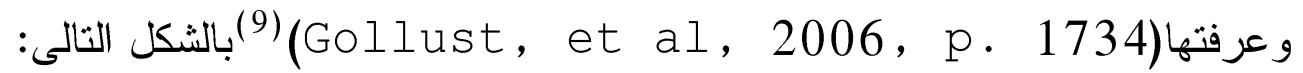

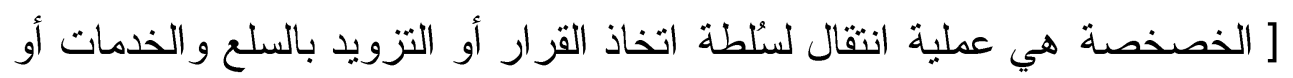

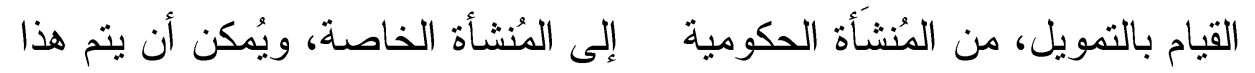

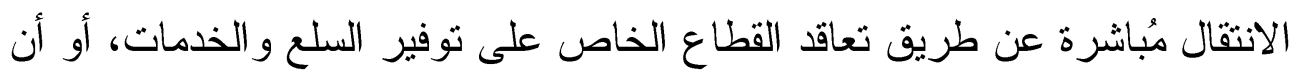

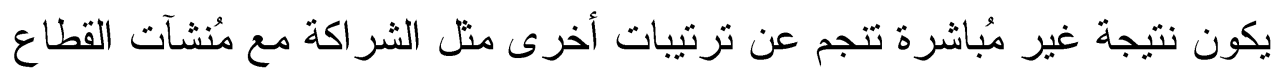

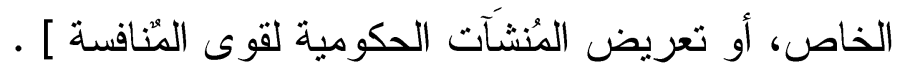

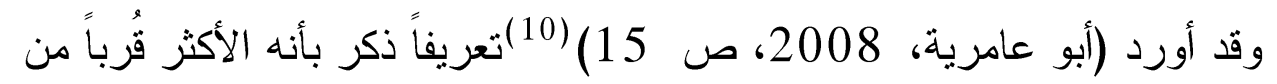

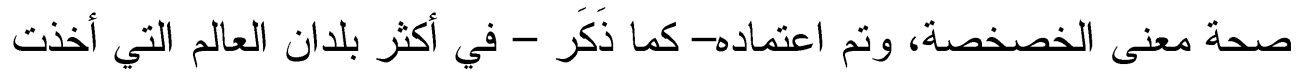

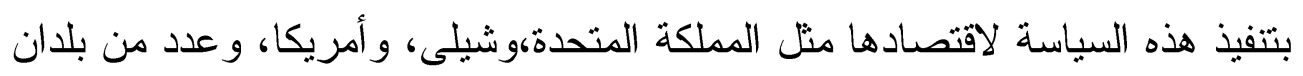

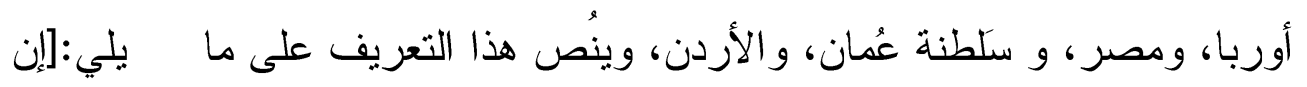

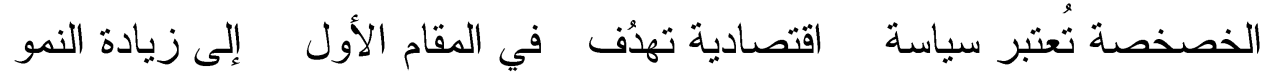
الاقتصادي بوجه عام، وذلك من خلال إعادة هيكلة الاقتصاد، و إعادة هيكلة

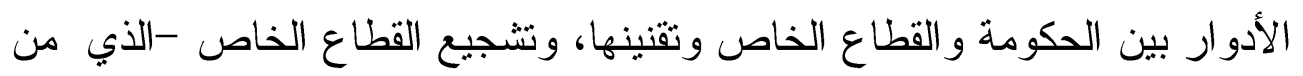
المُفترض أن يتميز عن القطاع العام بانخفاض درجة البيروقر اطية فياتخاذ القرارات

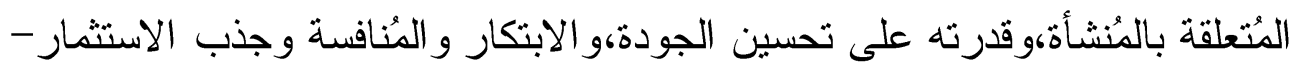

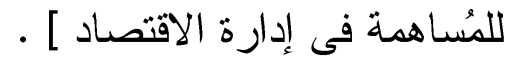


بجلةجامعةُ مدرمان الإسلامية (العدد السابعوالعشرونوالثاني عشر الكترونيا) العام 1437هـ 2015م

2-1

وردت للخصخصة العديد من الأوصاف،نوجز ها فيمايلى :

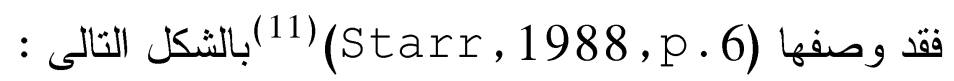

] إن الخصخصة مُصطلح فضفاض و غير و اضح، شمل مدى و اسِع من الأفكار

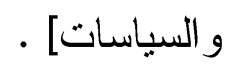

ووصفها (12) (12) بما

يلى

(إن الخصخصة عملية صعبة، ومحفوفة بالصِر اعات وتضاربب المصالح). وذكر (Tatahi, 2006, p. 6.

[أن (Heald, 1983, p. 298) لمجموعة من السياسات تربطُها بطريقة فضفلفة للتعبير عن تعزيز قوى السوق على حساب الدولة]. 3-1 الأهداف العامةللخصخصة كثيرة ومنها: (1) تحسين الكفاءة الإنتاجية للمنشأة العامة. (2) تحقيق إير ادات مالية للدولة.

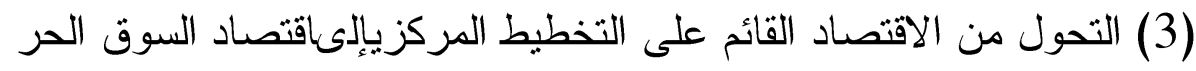

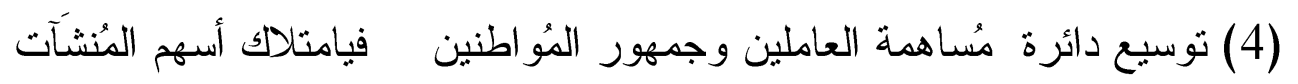

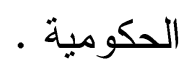
(5) مكافحة الفقر، وتقليل الفوارق في مُستوى التتمية بين أقاليم البلاد. 


\section{د. عبد الله الطيبنموذج استراتيجي للخصخصة الناجحةص:282_يـــ}

(6) إعادة تحديد دور الدولة لتمكينها من التركيز على التحكُ موالانضباط و الإدارة - (Governing)

(7) تقوية (Strengthening) دور القطاع الخاص فيالاقتصادالوطني . أما الأهداف الثانوية فمنها : أنوانه (8) تحقيق مكاسب سياسية للسئلة الحاكمة. (9) إضعاف نفوذ النقابات العمالية.

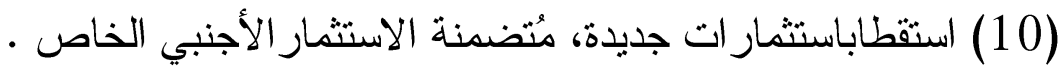

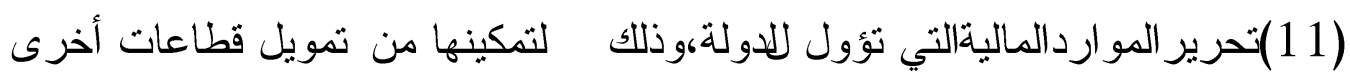
مثل التعليم و الصحة وخلافها. و على وجه العموم فإن الأهداف هى المعيار الأساسي (benchmark) الذي ينت بموجبه قياس فاعلية بر امج الخصخصة، و وأساس المُفاضلة بين الأساليب البديلة

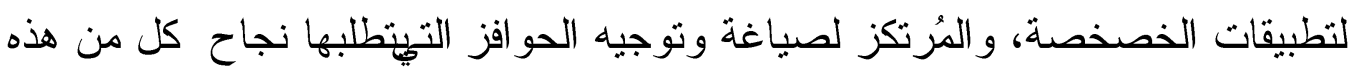

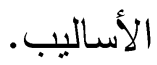

\section{1-4 مُتطلبات نجاح الخصخصة في الاول النامية:}

إن الوصول إلى خصخصة ناجحة يتطلب إحداث تطور سريع وشامل وفاعل فى لهى الإطار الكلى ( macro -level ) الذي ينم فيه تصميم

وتتفيذبر امجالخصخصة،وذذلكبتوفير المتطلبات (prerequisites) التالية :

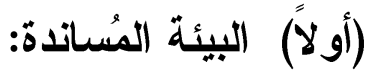
وتشتمل البيئة المُساندة على ما يلى:

(1) البيئة السياسية المُستقرة .

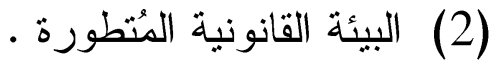

(3) البيئة الاجتماعية المُرحبة بقيام المزيد من الأنشطة الاقتصادية . (4) بيئة الأعمال الجاذبة . 
بجلةجامعةأمدرمان الإسلامية (العدد السابعوالعشرونوالثاني عشر الكتونيا) العام 1437هـ 2015م

(ثانياً) (الضوابط الأساسية لنجاح الخصخصة :

وتشتمل الضو ابط الأساسية لنجاح الخصخصة على النوجودمايلى:

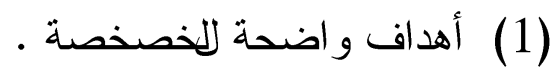

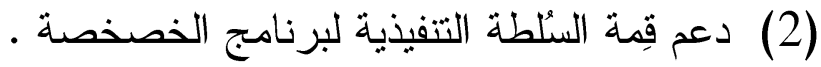

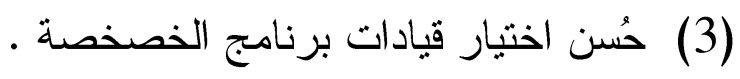

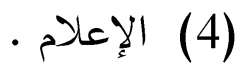

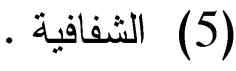

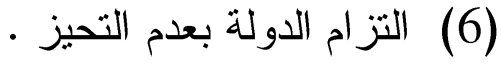

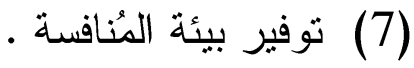

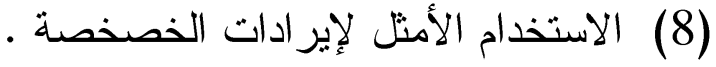

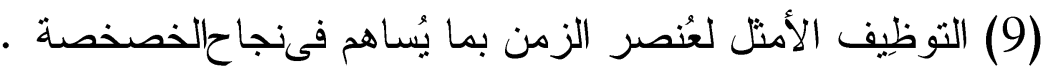

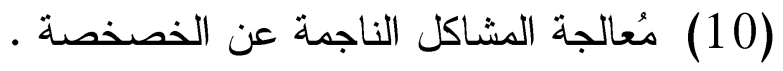

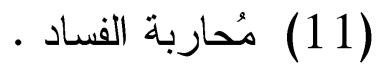

(12) كفالة حق التعبير لـُنظمات المجتمع الدولى .

(ثالثاً) الخطوات التنفيذية لعمليات الخصخصة :

و تشتمل الخطو ات التتفيذية لعمليات الخصخصة على ما يلى :

. (1)

(2) النظر فيلهمية إعادة تأهيل المُنشَأة .

اختيار الأسلوب التطبيقي المُناسب للخصنصة إعضدة.

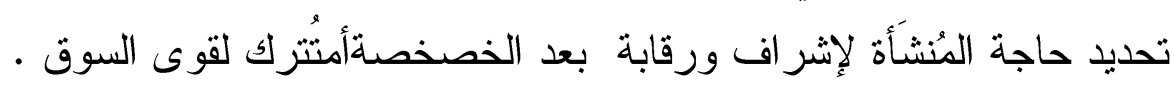

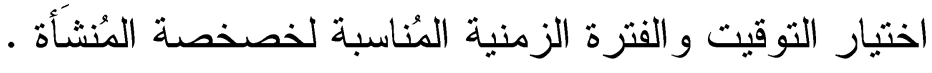




\section{د. عبد الله الطيبنموذج استراتيجي للخصخصة الناجحةص:282_يـــ}

(6) تحديد مُو اصفات الجهة الاستثمارية المُستهدفة بالخصخصة.

\section{1-5الأساليب التطبقية للخصخصة :}

ورد في الأدبيات أن للخصخصة العديد من الأساليب التطبيقية، كما ورد أيضاً أن

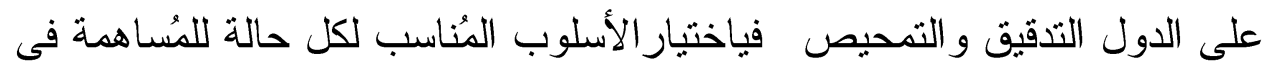
نجاح هذه النطبيقات وذللك في ضوء مايلى :

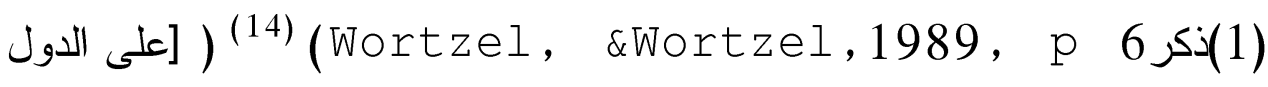
أن لانُركز تفكير ها فقط في تحقيق الخصخصة - نقل المِلكية - بل عليها أن تُفكر

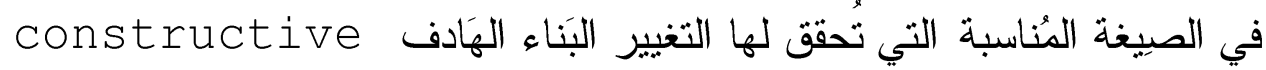

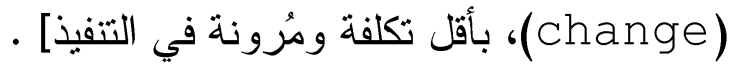

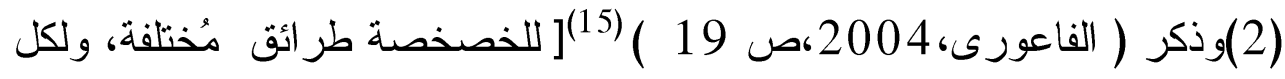
طريقة من هذه الطر ائق مز اياها و عيوبها، ويُعتبر اختبار الطريقة المُناسبة من أهم

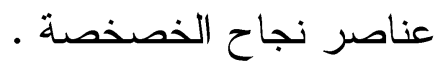
(3)وذكر ( Donaldson,2007, p. 472Fafaliou\& (16) (ينبغى تفصيل أساليب الخصخصة حَب الظُروف السائدة فى البلا المعنى ].

\begin{tabular}{|c|c|}
\hline الطرق الفرعية & الأسالي التطبيقية الرئيسة للخصخصة: \\
\hline البيعeale & \\
\hline $\begin{array}{l}\text { Free Transfer الإحالة (الهبة) التصفية Liquidation } \\
\text { Liqua }\end{array}$ & إنهاء ملكية|الدولة Divestment \\
\hline
\end{tabular}




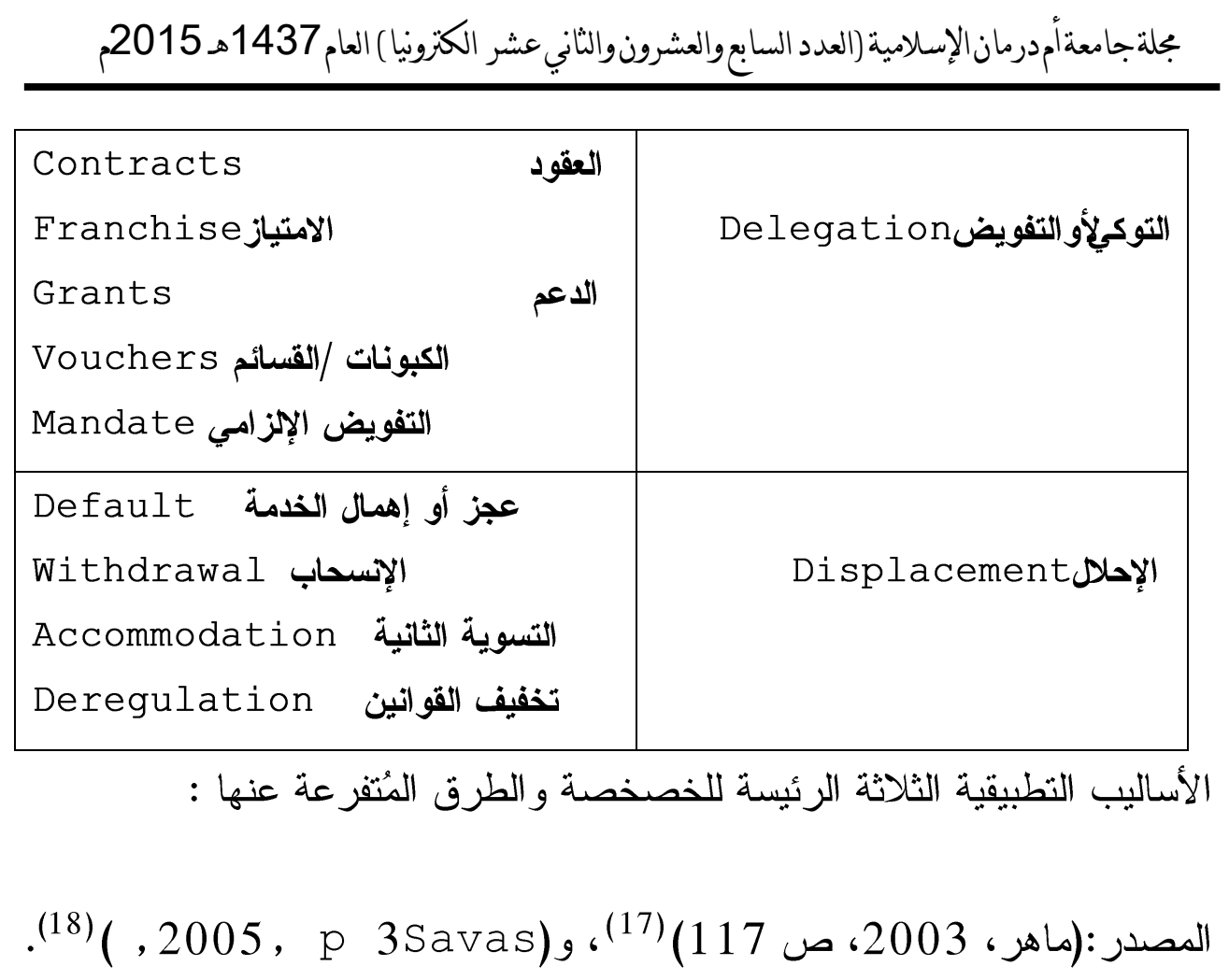




\section{د. عبد الله الطيبنموذج استراتيجي للخصخصة الناجحةص:312-282.}

\section{المبحثالثاني}

\section{الأبعاد الاولية لتطبيقات الخصخصة}

1-2 أسباب انتشار تطبيقات الخصخصة عالمياً :

وتتلخص أسباب انتشار تطبيقات الخصخصة عالمياً فيما يلي :

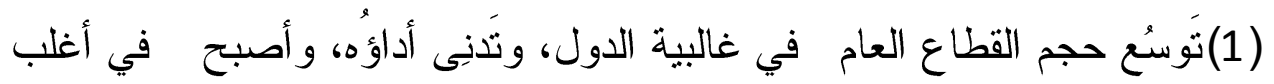

$$
\text { الأحيان عبئًا على خزينة الدولة . }
$$

(2) الأوضاع الاقتصادية القاسية التي سَادت غالبية دول العالم (الغنية والفقيرة ) . (3)حالة الرُكود التضخمي (stagflation) التي شهدتها الدول المُتقدمة و التي اتسمت بارتفاعكلمن مُعدلات التضخم و البطالة مصحوبة بتندي معدلات النمو الاقتصادي، والبحث لها عن علاج عاجل.

(4)حالة اختلال موازين المدفوعات و الديون الخارجية التي أرهقت الدول النادئ النامية. (5)ظهور الشركات مُتعددة الجنسيات، واتساع حركة رؤوس الأموال الأجنبية الباحثة عن فرص استثمارية خارج دولها.

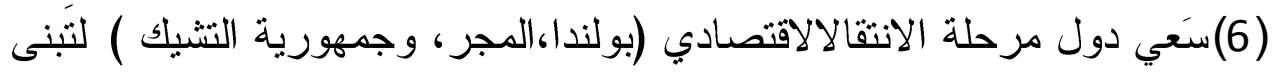

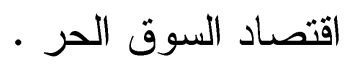

(7) الضُغوط التي مَارستها المُؤسسات المالية الدولية على الدول النامية لتطبيق

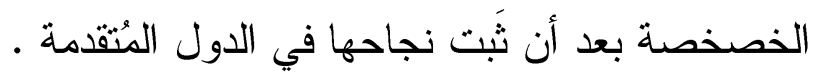


بجلةجامعةأمدرمان الإسلامية (العدد السابع والششرونوالثاني عشر الكترونيا) العام 1437هـ 2015م.

2-2 هل أداء القطاع الخاص أفضل من أداء القطاع العام ؟ :

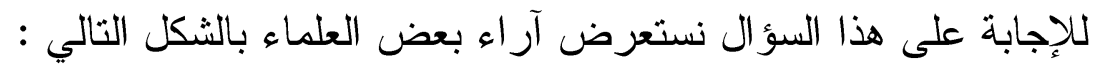

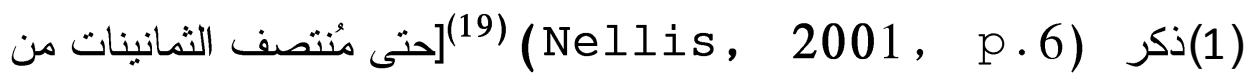
القرن الميلاديالماضي لم تكن هنالك شو اهد تجريبية يُعتد بها، وذات

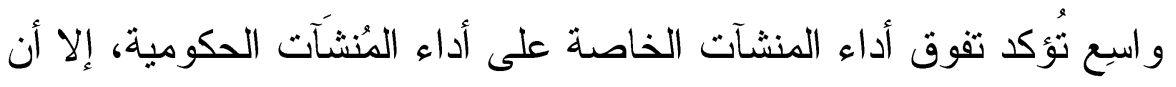

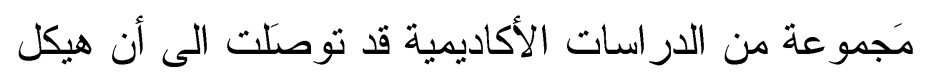

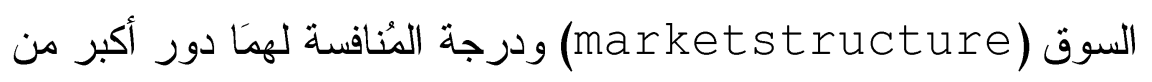
الملكية فى تحديد مُستوى الأداء و الكفاية الإنتاجية ] [ ل

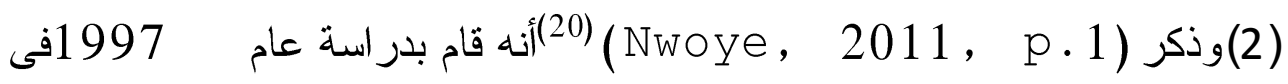

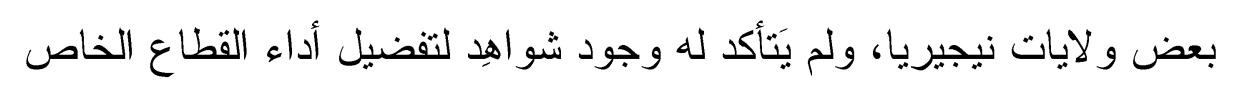

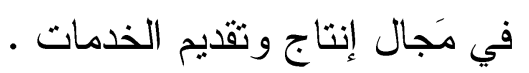

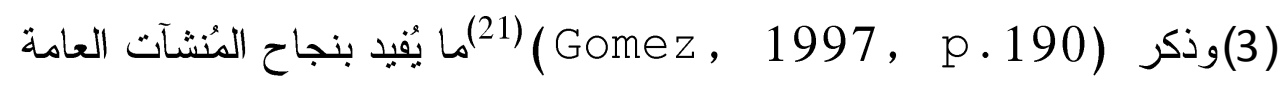
في كل من سينغافورة، ونايوان، وكوريا الجنوبية، وشركة بتروناس الماليزية

$$
\text { و الثركات المُتَفر عة عنها. }
$$

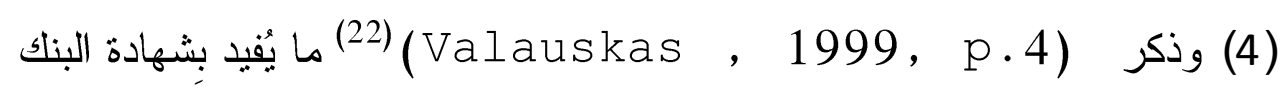

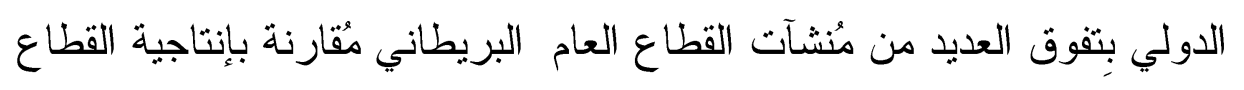

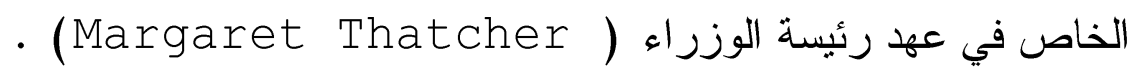

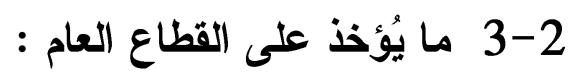

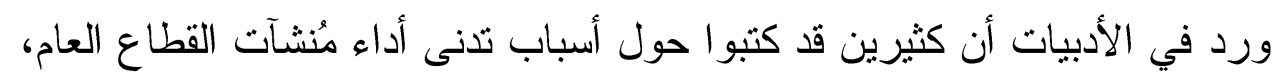

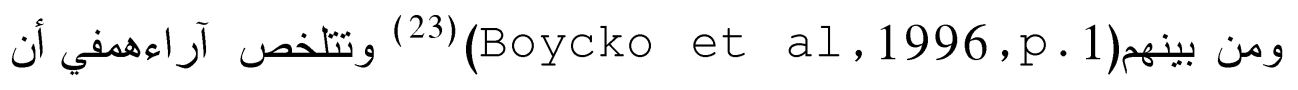

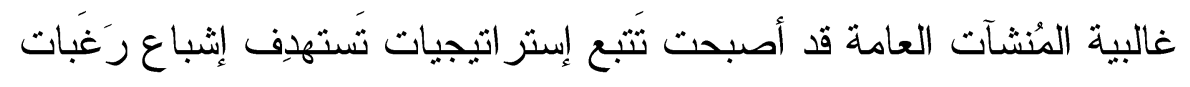




\section{د. عبد الله الطيبنموذج استراتيجي للخصخصة الناجحةص:282_يـــ}

السياسيين الذين يُشرفون على إدارتها، حيث أصبحت تَستجيب إلى توظيف عمالة أكثر من حاجة العمل، وتحديد أسعار للسِلع و الخدمات التىنتتجها أقلى من تكَلفتها الفعلية .

2-4 موقف الدول المُتقدمة من الخصخصة :

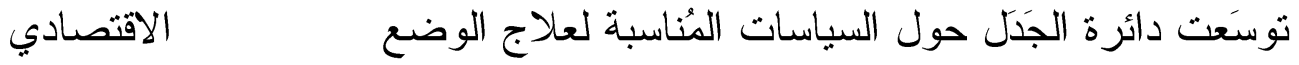
ي

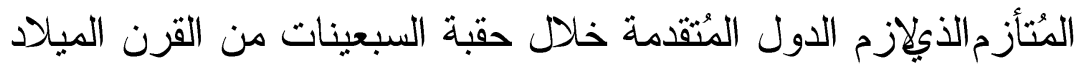
الماضي،خاصة وأن العيوب البيرُوقر اطية - فى نظر البعض - ليست أقل تكلفة

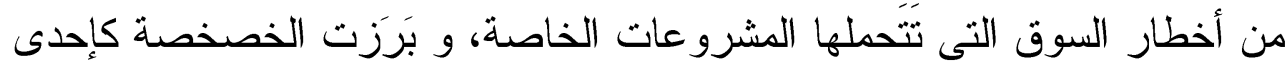

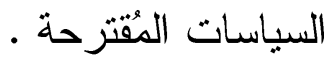

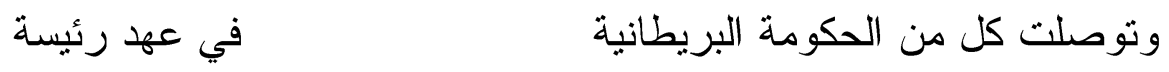

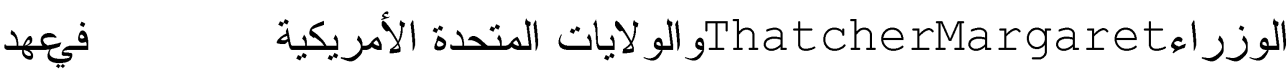
الرئيسRoland Reaganإلى أن كِرَر حجم الدولةهو السَبب الأساسيفي ظُهور

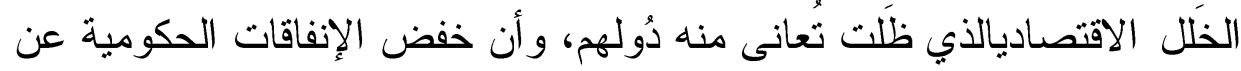
طريق المَزيد من التحول إلىقاقتصاد السوق هو الحل المُناسب، وذلك وفقاً لما ذكره . (24) (Chang, 2006, p.5) وبادرت الحكومة البريطانية بإصدار مَجموعة من السياسات الإصلاحية عُرفت

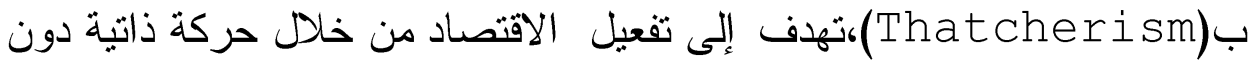
تدخُل مُباشر من الدولة،هوتضمنت مايلي :

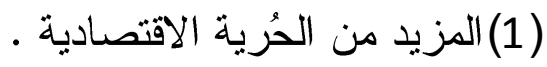

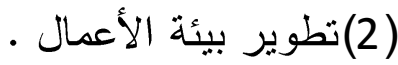
(3) تعزيز المُنافسة و الثشفافية .

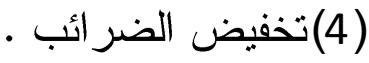

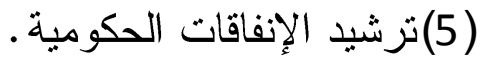


بجلةجامعة أمدرمان الإسلامية (العدد الساجع والعشرونوالثاني عشر الكترونيا) العام 1437هـ 2015م.

(6) إجر اءإصِلاحات في سُوقالأوراق الماليةالذي تأسس عام ألمات 1801م.

(7) الإفصاح عن نية الحكومة في تطبيق الخصخصة و السياسات

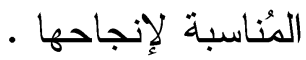

وفى الو لايات المتحدة الأمريكية تم تطبيق سياسات إصلاحية مُشابهة

ع عُرفتب (Reaganism) م الايات

2-2 موقف الاول النامية من الخصخصة:

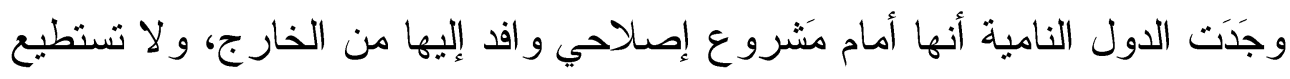

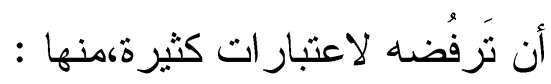

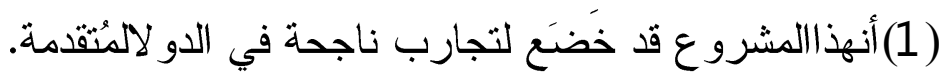

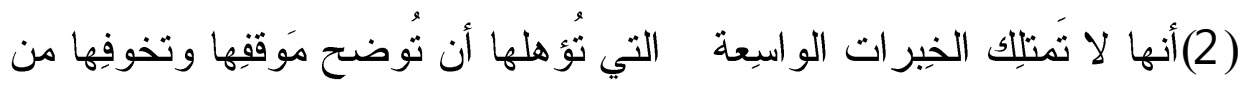

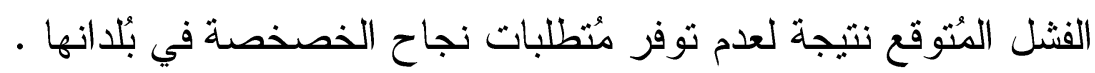

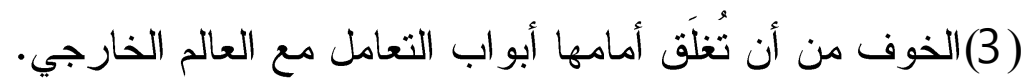

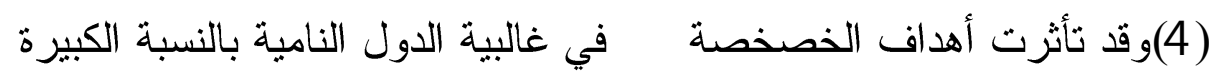

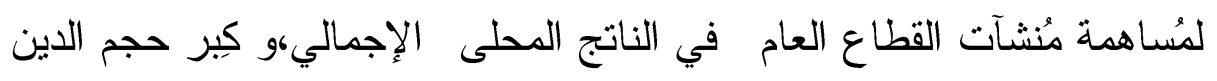

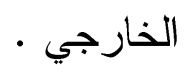

(5)أما غالبية دول مرحلة الانتقالالقتصادي(دول المُعسكر الاشتراكي سابقاً ) فقد

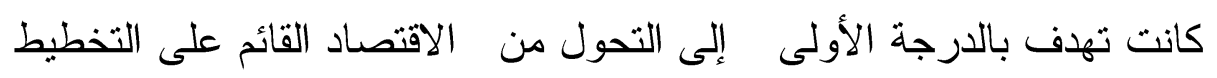

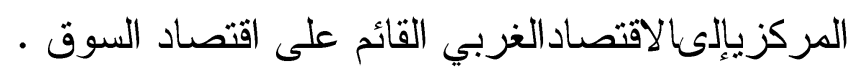

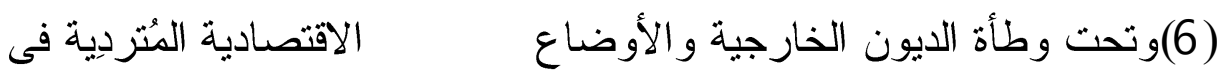

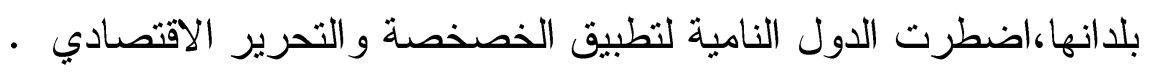




\section{د. عبد الله الطيبنموذج استراتيجي للخصخصة الناجحةص:282_يـــ}

6-6 موقف المُؤسسات المالية الاوليةمن الخصخصة : يُكن تلخيص موقف المُؤسسات المالية الدولية من الخصخصة بالثكل التالي :

(1) ساهم البنك الدولي خلال الفترة 1960-1980 في تشجيع غالبية الدول

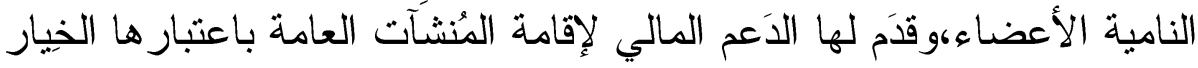
المُناسب لتحقيق الوفورات المالية اللازمة لاستغلال مواردِها الطبيعية، و إقامة

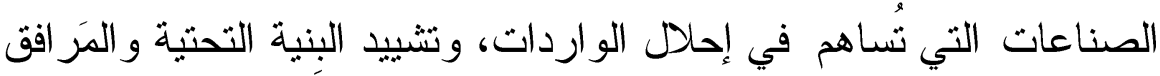

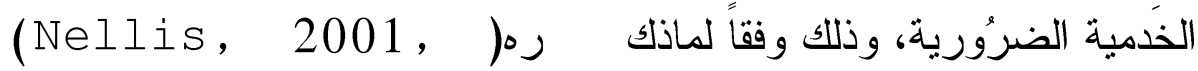

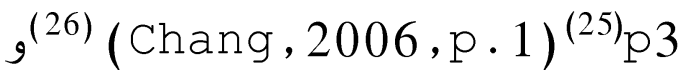
(27) (Fafaliou\&Donaldson, 2007, p. 464 اتخذت المؤسسات المالية الدولية في نهاية الثمانينات من القرن

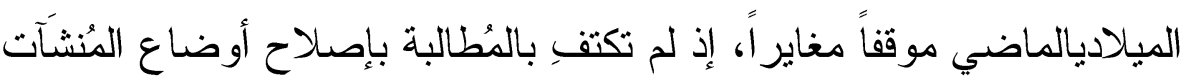

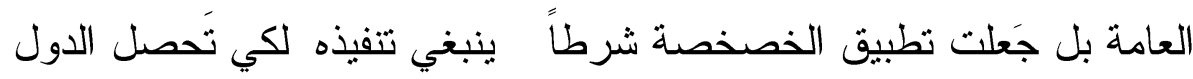
ك النامية الأعضاء على المُساعدات المالية الدولية، وذل

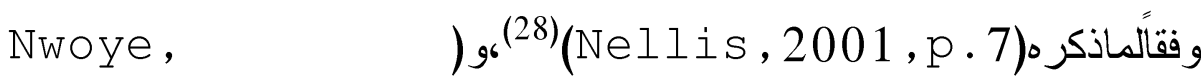
. $^{(29)}(2011$, p. 3 ذكر (نيلليس، 1999، ص 18)(30) [ لا بُد أن تتحمل المُؤسسات المالية

الدولية بعض المسئُولية عن هذه النتائج الضعيفة لأنها طالبت حكومات البلدان التي تَمُر بمرحلة انتقال بتحقيق الخصخصة بِسرعة وعلى نطاق واسع ]. و أضاف (Nellis, 2005 , p . 17) القرن الميلادي المُنصرم اتجه كل من البنك الدولي وصندوق النقا

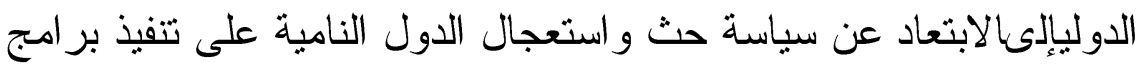
الخصخصةفي بلدانها]. 
بعلةجامعةأمدرمان الإسلامية (العدد الساجو والعشرونوالثاني عشر الكترونيا) العام 1437هـ 2015م.

(32)(Fafaliou\& Donaldson, 2007, p. 462) وذكر (5) [إن البنك الدولي قد بدأ يستشَعر خطأ اعتقاده بأن الخصخصة مَهُها كان

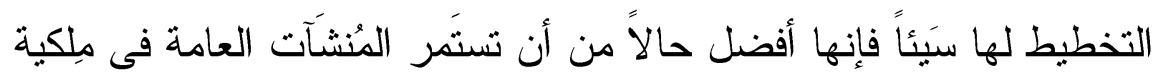

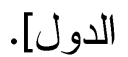

Roland, 2008, pp. $\quad 1-\quad$ (6)

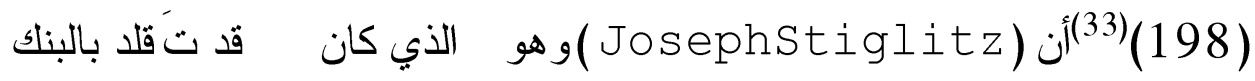
(Senior Vice President \& Chief الدوليوظيفةوالحائز EConomist 1997-2000 (على جائزة نوبل فيالاقتصادعام 2001 أنه قال [.... بالرغم من أن الخصخصة قد حققت العديد من الإنجازات إلا أنها

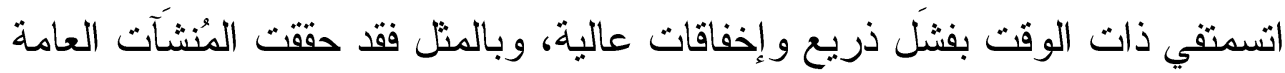
نجاحات كبيرة وإخفاقات عالية، فالأسئلة التي تحتاج إلى إجابة الآن هي:

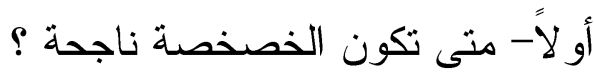
ثانياً - كيف يُكن أن تُدار عمليات الخصخصة لنُحقِق أقصىى احتمالات

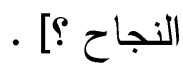


د. عبد الله الطيبنموذج استراتيجي للخصخصة الناجحةص:282_ي

\section{المبحث الثالث}

الخصخصة الناجحة

3-1-3 الإستر اتيجية المُقترحة للوصول لخصخصة ناجحة :

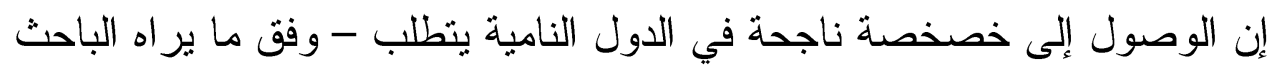
- إحداث نطور سريع وفاعل على مستوى الإطار الكلي ( macro - level)

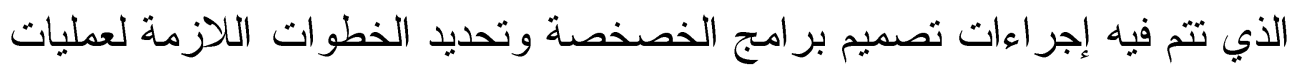

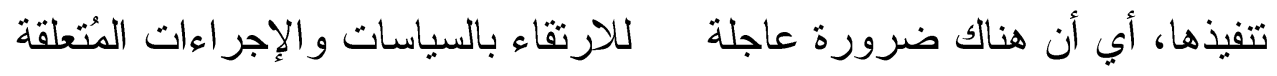

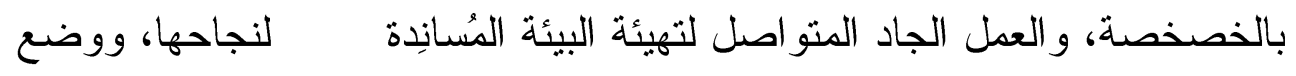

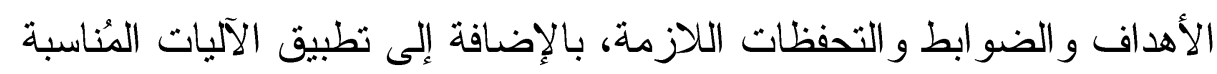

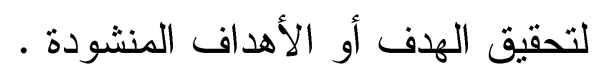

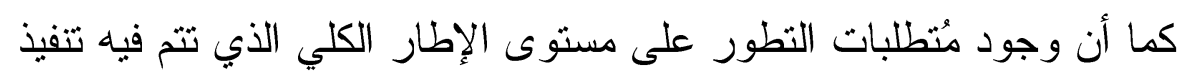

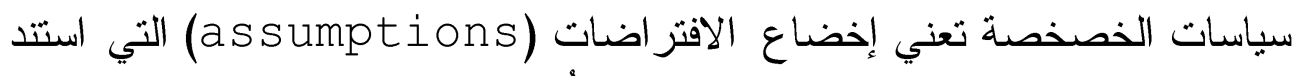

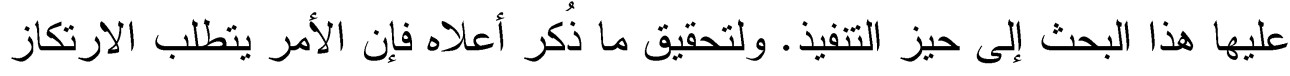

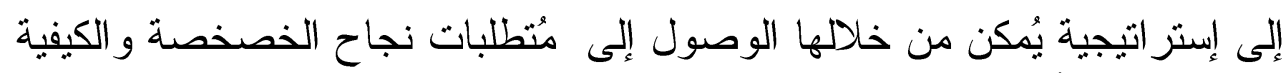

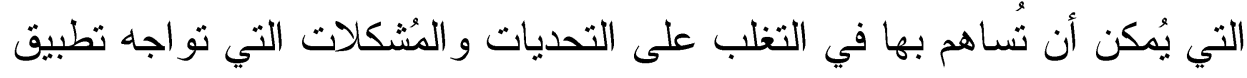

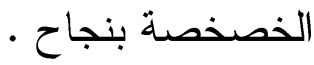

\section{3-2 الخطوات التي تم إتباعها للوصول لمُنطلبات نجاح الخصخصة:}

لاستخلاص مُنطلبات نجاح الخصخصة و التحقق من سلامتها فقد أرتكز هذا البحث على القز اعة المُتأنية و الفحص الدقيق لما تضمنته المصادر العلمبة ذات الموثوقية

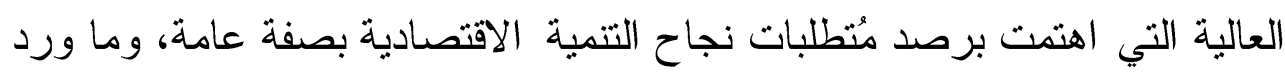
بشأن الخصخصة بصفة خاصة، وغير ها من المصادر الموثوقة ذات العلاقة. 
بجلةجامعقأمدرمان الإسلامية (العدد السابعوالعشرونوالثاني عشر الككرونيا) العام 1437هـ 2015م.

و المو اد العلمية التي تم استهافها بالقراءة العُتَٔنية و الفحص الدقيق قد تم تجميعها في

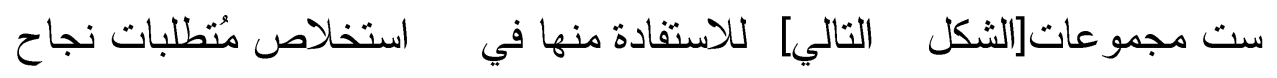

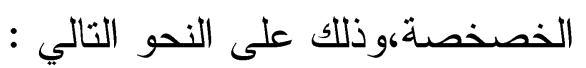
أولاً - التعريفات ( definitions) التي أوردها كل من البنك الدولي،

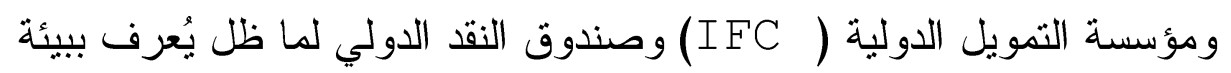
الاستثمار الجاذبة أو مناخ الاستثمار الجاذب التبان

(Conducive environment or favorable investment climate) ثانيا- أدبيات البحث وخاصة الجدل الذي ظل دائراً حول أسباب نجاح أو فثل

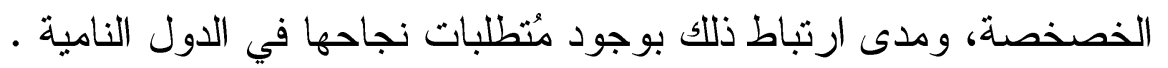

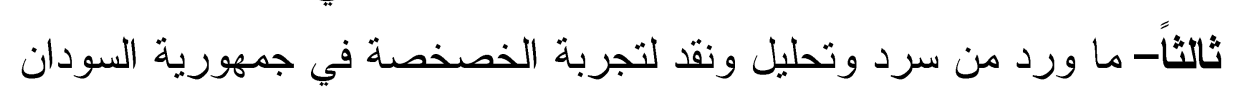
ومجموعة من الدول الأخرى، والدروس المُستفادة منها بالإضافة إلى ما تضمنته

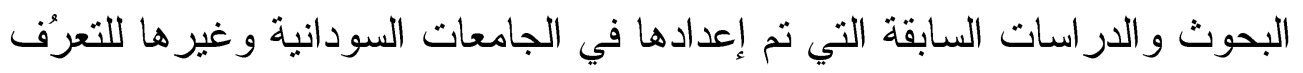

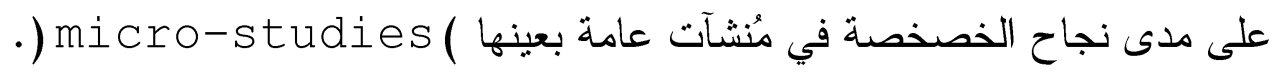

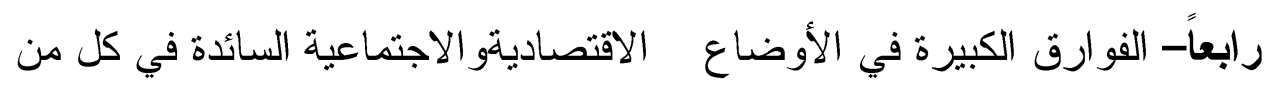

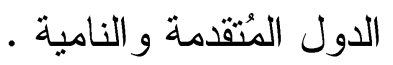
خامساً- المنافع المُتوقع تحقيقها للأطر اف الأربعة المُشتهوفة بالاستفادة من إيجابيات

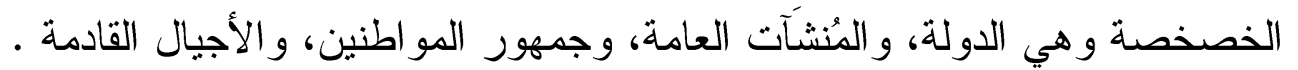

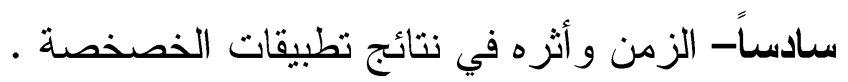




\section{د. عبد الله الطيبنموذج استزاتيجي للخصخصة الناجحةص:312_ي}

\section{شكل يوضح الخطوات التي تم إتباعها للوصول لمتطلبات نجاح الخصخصة :}

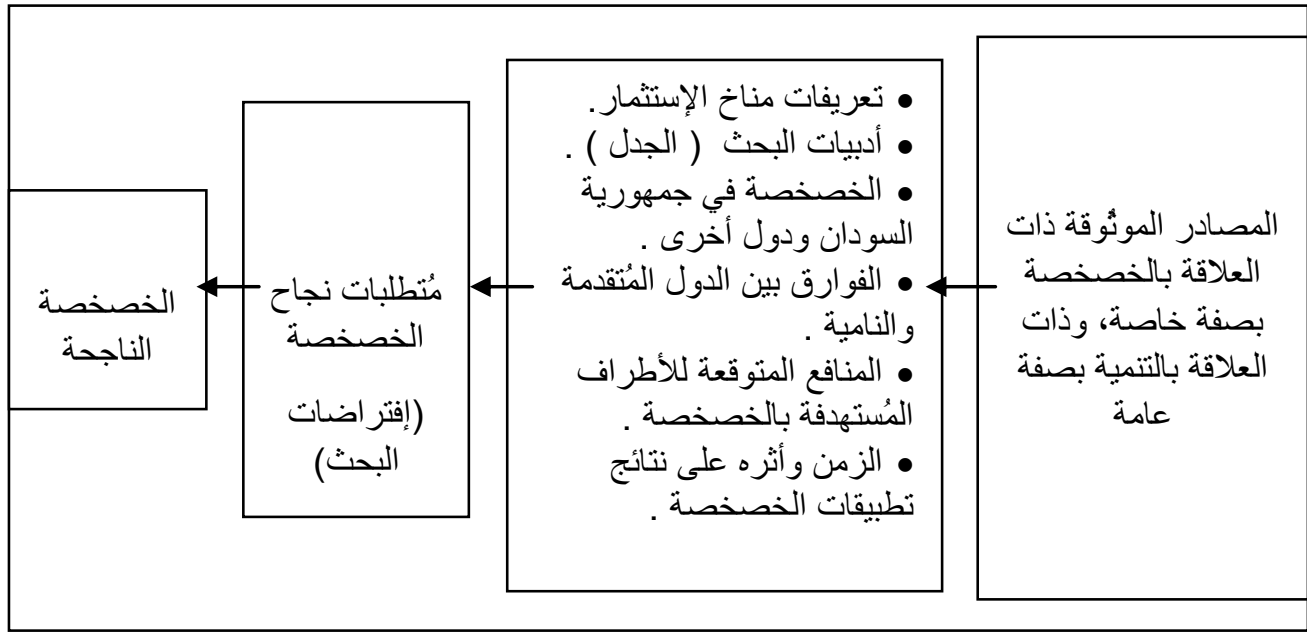

$$
\text { المصدر :إعداد الباحث. }
$$

3-3نموذج إستر اتيجي للخصخصة الناجحة :

النموذج المقتر ح يُعبر تعبيراً منطقياً عن العلاقة بين الخصخصة الناجحة ومُّطلبات نجاحها، ويُلبي تطلُعات الأطر اف المُستهدفة بالاستفادة من إيجابيات الخصخصة، ولهذا فإنه يُمَكِن صنّاع سياسة الخصخصة ومُنفذو ها من التعامل معها بأفق أوسـع

وضو ابط مُحكمة، وجدية أكثر مدا يُوسع دائرة النجاح، و يُضيِّق فُرص الفشل . 


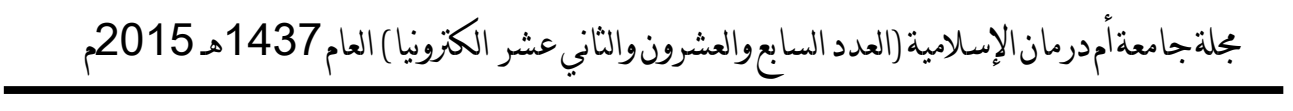

شكل يوضح النموذج الإستر اتيجي المُقترح للخصخصة الناجحة:

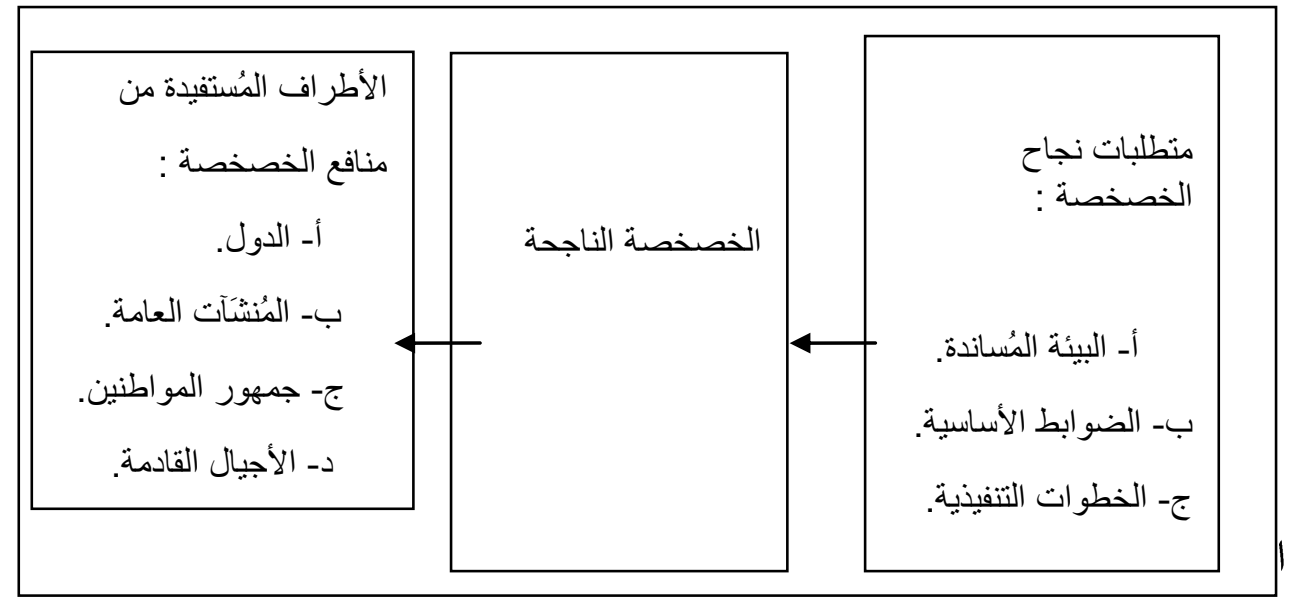

وبهذا يأمُل الباحث أن يكون قد وُفقَ في تقديم نموذج إستر اتيجي للخصخصة الناجحة(successful privatization) تهندي به الدول النامية و هي مُطمئنة بأنها تسير في الاتجاه الصحيح دون انحر اف حفاظاً على المال العام، وحماية للمنافع التي يُتوقع أن تؤول للأطر اف المُستهدفة بالاستفادة منالخصخصة و هي الدول، والمُششَّت الاقتصادية، وجمهور المواطنين، و الأجيال القادمة. 


\section{د. عبد الله الطيبنموذج استراتيجي للخصخصة الناجحةص:282_يـــ}

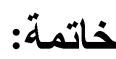

النتائج :

(1)إن تتفيذ الخصخصففي الدول النامية بالثكل الصحيح مرهون بتوفير منطلبات

(2) من الأهمية بمكارعم قِمة السُّلة التنفيذية لبر امجالخصخصة في بلدانها. (3)|تضح أن نجاح تصميم وتتفيذ بر امج الخصخصة يَتَطلَب حُسن اختبار

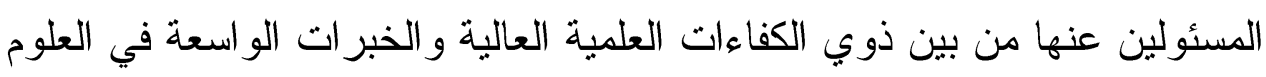

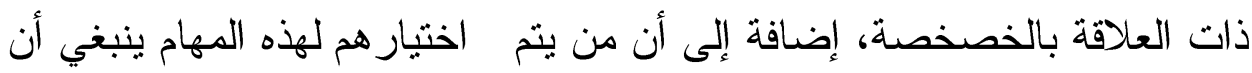

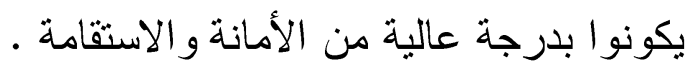

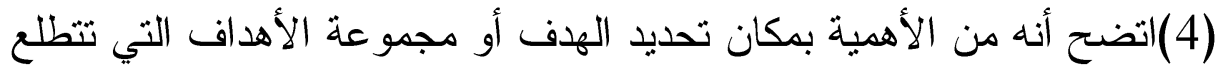

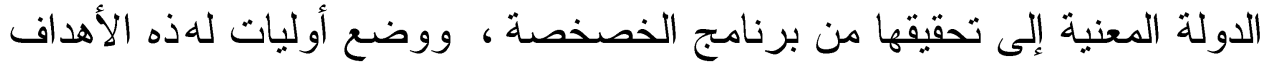

$$
\text { بشكل و اضح ومحدد. }
$$

(5)كثفت تجارب الخصخصة في بعض الدول وخاصة في أفريقيا جنوب

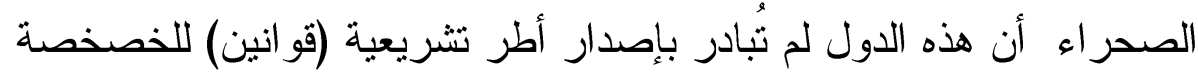

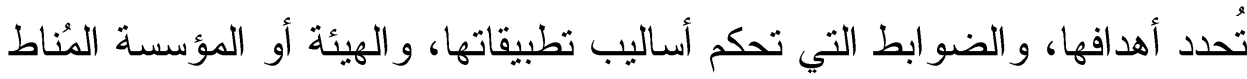

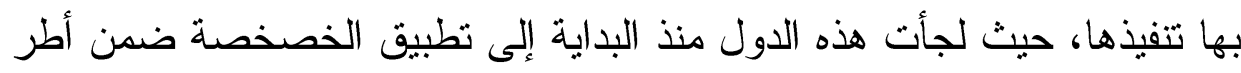

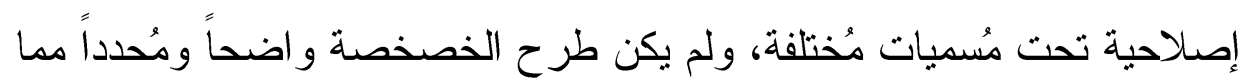
أعاق سرعة تتفيذها، وجعلها عُرضة للأخطاء، وأدى إلى تدني مستوى أدائها وتوقفها أكثر من مرة كما حدث في يو غندا، وجنوب أفريقيا، ونيجيريا، و والأرجنتين. 
بجلةجامعةأمدرمان الإسلامية (العدد السابع والعشرونوالثاني عشر الكترونيا) العام 1437هـ 2015م.

(6)إن الخصخصة آليةلتحسينأداء المُنشآت الحكومية، حيث إن المُنشآت الخاسرة

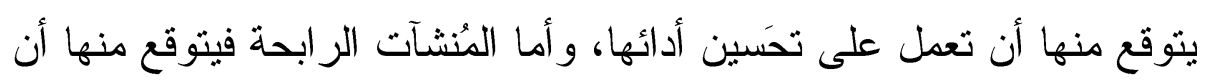

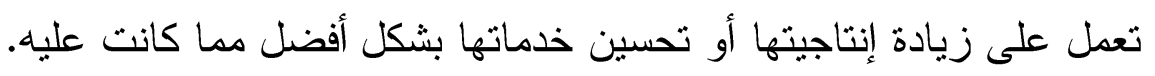

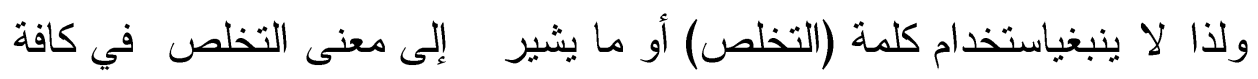

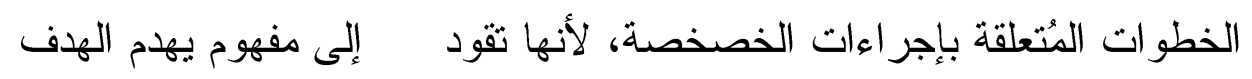

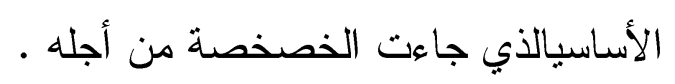
(7)ثبت أن استير اد الخصخصة كإطار جاهز يصلُح تطبيقه على كل الحالات الخدات

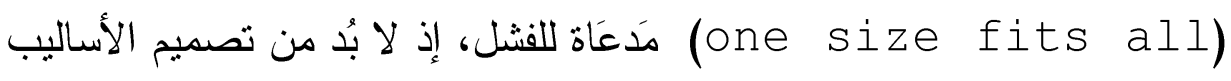

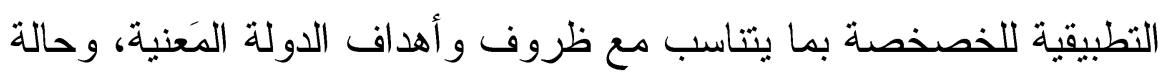

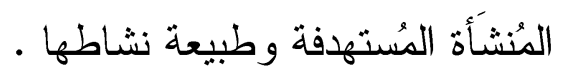

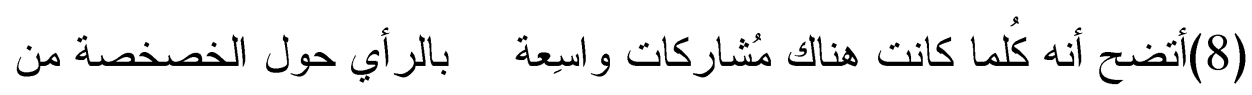

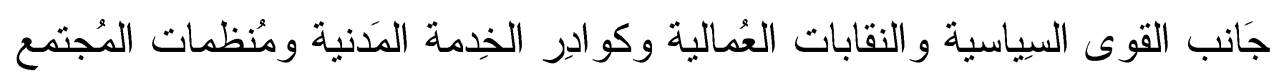

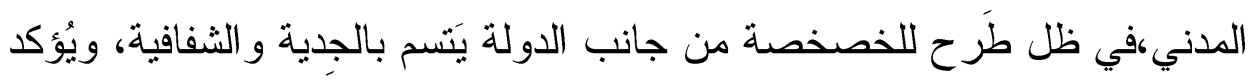

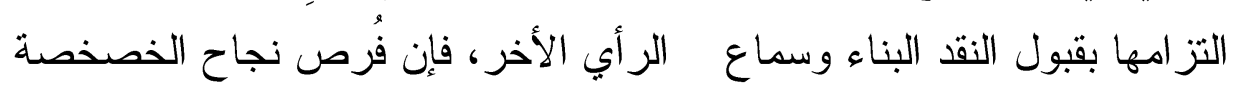

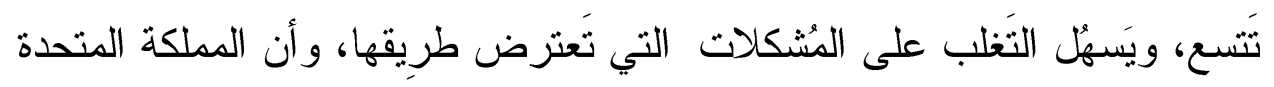

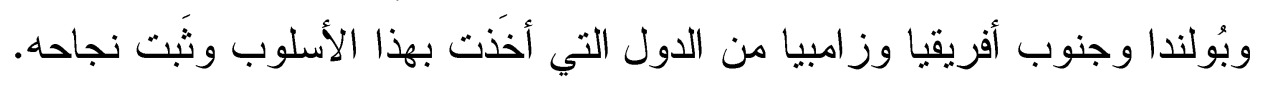

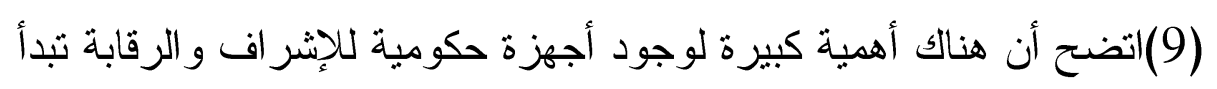

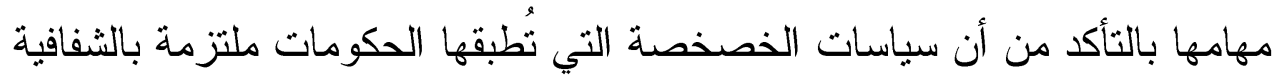

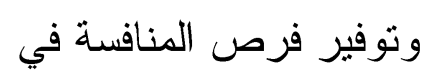
ظل قيام الدولة بكسر الاحتكار الحكومي أو الخاص لبعض العناف الأنشطة أو كلها،

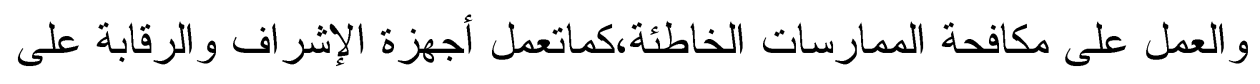

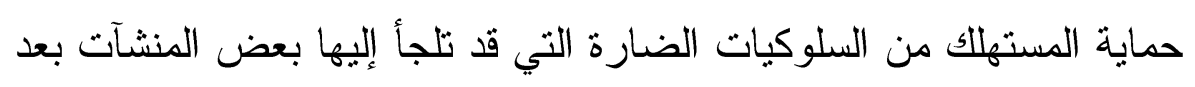




\section{د. عبد الله الطيبنموذج استراتيجي للخصغصة الناجحةص:312:}

الخصخصة، خاصة في حالة أن تكون المنشأة ذات وضع احتكاري أو أن المنافسة

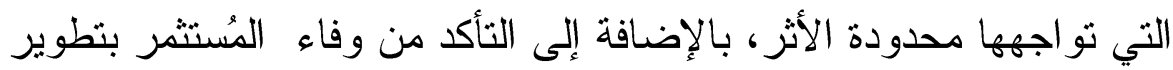
المنشأة إذا كان ذلك ضدن الشروط التي تم الاتفاق عليها.

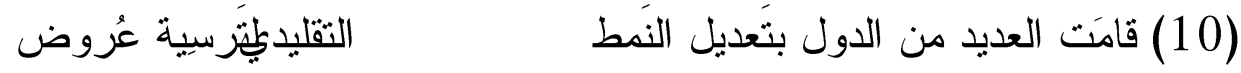

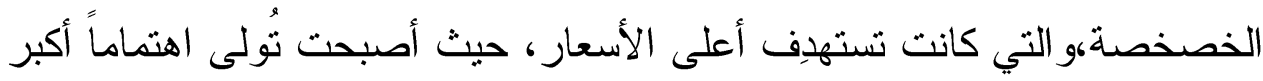

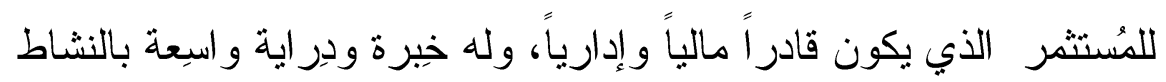

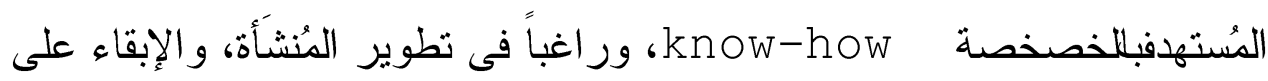

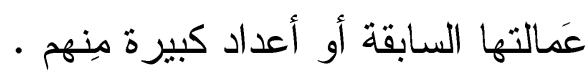

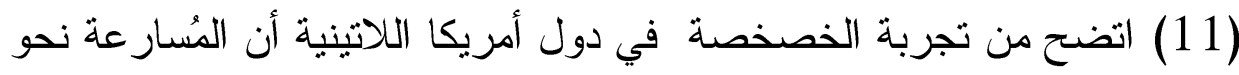
تحقيق هدف مُعالجة مُشكلة الديون الخارجية قد دَفع هذه الدول وخاصة الأرجنتين

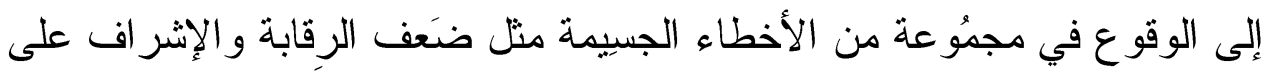
عمليات الخصخصة ، و عدم الرقابة على المُنشآت ذات الطبيعة الاحتكارية بعد

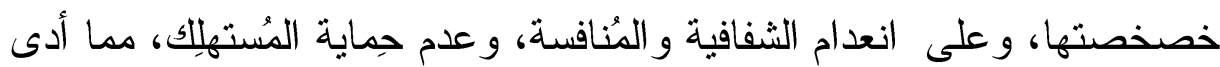

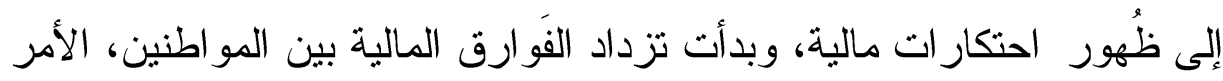

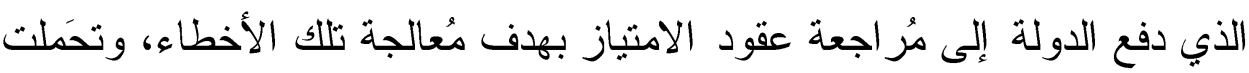

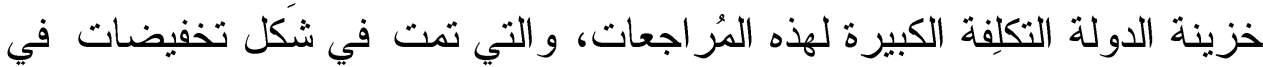

$$
\text { الضر ائب وبعض التسهيلات الأخرى. }
$$

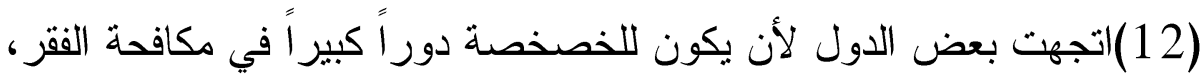

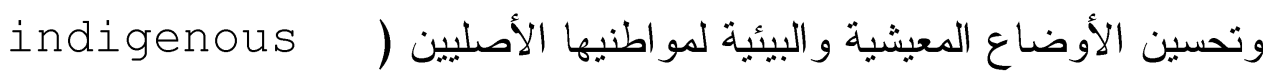
races

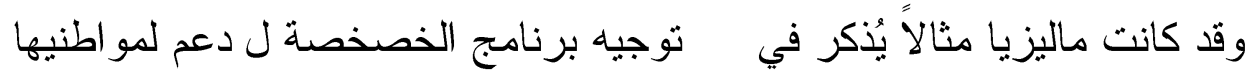

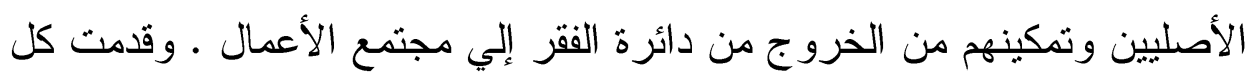




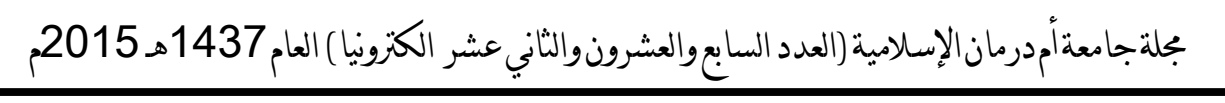
من جمهورية الثشيك، وتشيلي، وجنوب أفريقيا، وزمبابوي نماذج أخرى تهدف الفري

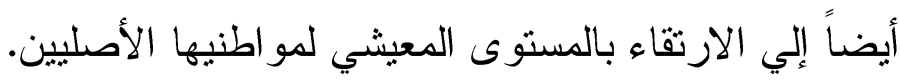

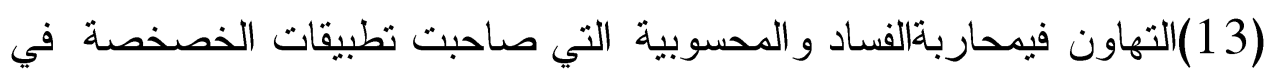

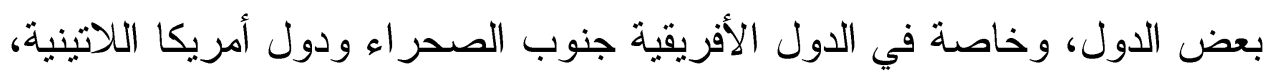

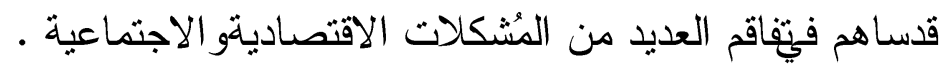

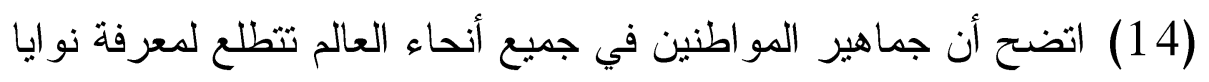

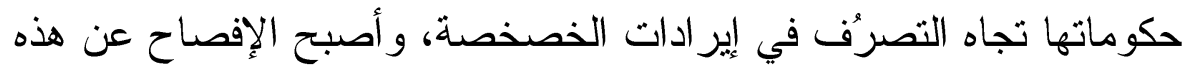

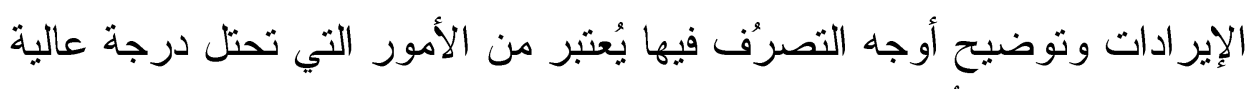

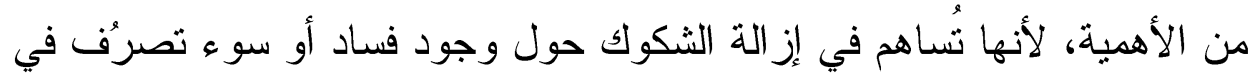

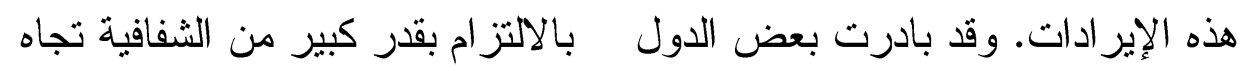

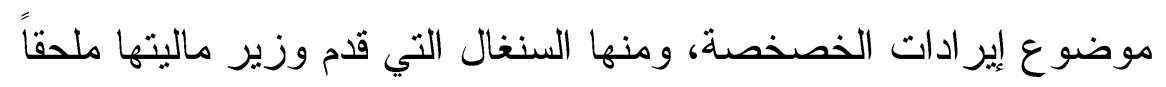

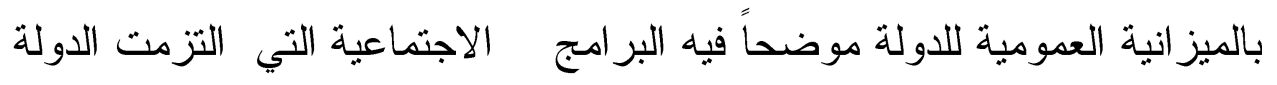

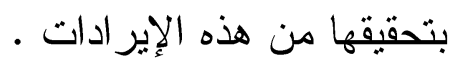

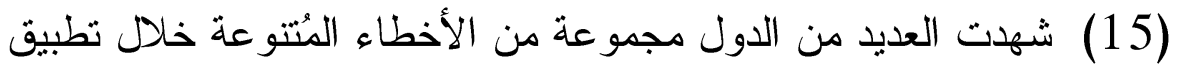

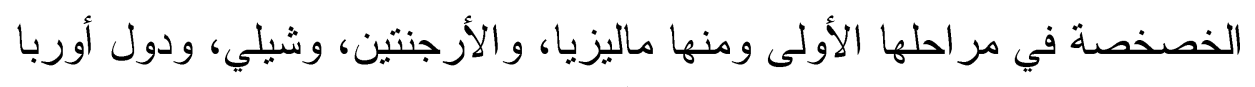

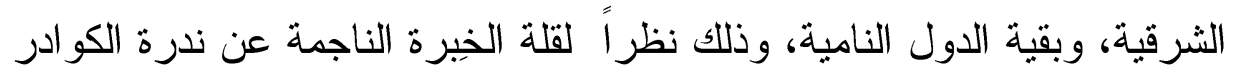

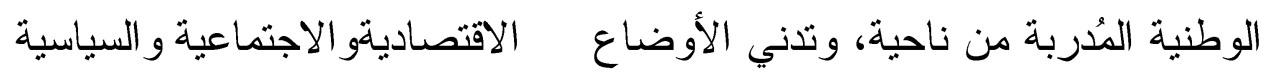
لبعض الدول من ناحية ثانية، بالإضافة إلى تندي الأوضاع المالية المالية والإدارية

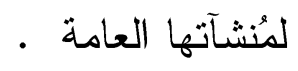

(16)استفادت العديد من الدول من نتائج التجارب الدولية فيطبيقات الخصخصة

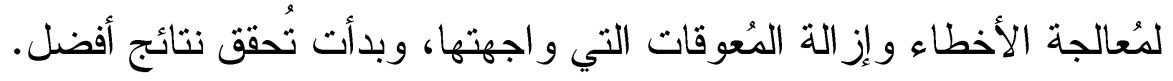




\section{د. عبد الله الطيبنموذج استراتيجي للخصغصة الناجحةص:312.282}

$$
\text { التوصيات: }
$$

(1) نشر المزيد من التوعية و التعريف بِمخاطر الخصخصة، ومُنطلبات نجاحها على مُستوى قِمة السُلطة التتفيذية . (2) أن تحشد الدول النامية كل الطاقات المُككنة لتوفير مُنطلبات نجاح الخصخصة الواردة في هذا البحث.

(3)أن تولى الدول النامية المزيد من الاهتماملاختيار الأشخاص الذين سيعهد إليهر بمهام تصميم وتتفيذ بر امج الخصخصة.

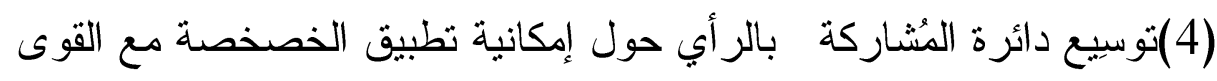

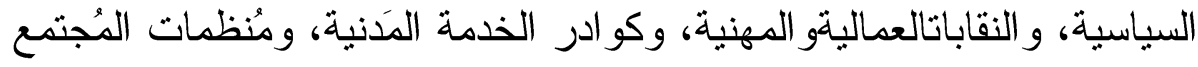

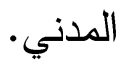
(5)أن يتم تصميم وتتفيذ برنامج الخصخصة وفق الأهداف المُعلنة للخصخصة،ووفق الظروف التي تعيشها الدولة، ووفق الأوضاع الر اهنة للمُنشآت التهات العامة، و هذا يَعنى أن الأساليب التطبيقية للخصخصة يتم تَفصيلها حسبَ الحالة و لاينبغي نقلها كأساليب جاهزة . (tailoring) (6)ينبخي أن ينت فهم الخصخصة على أنها آلية لتطوير أداء المنشآت الحكومية بحيث تشمل المُنشآت الخاسرة ليتم تحسين أدائها وتحويلها إلى منشآت رابحة، كما تشمل المُنشآت الر ابحة للمُحافظة على أرباحها و العمل على زيادة هذه الأرباح.

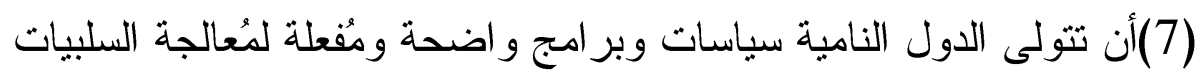

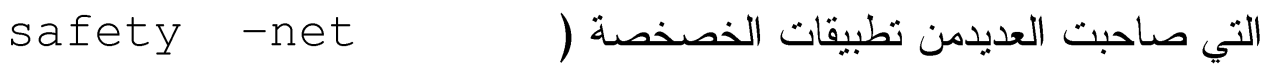

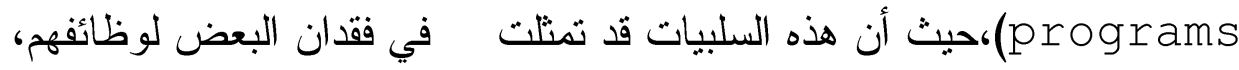

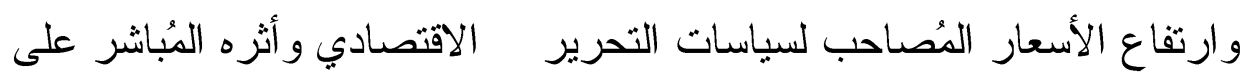
ذوى الاخول المُندنية. 
مجلةجامعةأمدرمان الإسلامية (العدد السابع والعشرونوالثاني عشر الكترونيا) العام 1437هـ 2015م.

(8)ينبغي أن يكون نركيز برامج الخصخصة على تحقيق هدف نطوير أداء

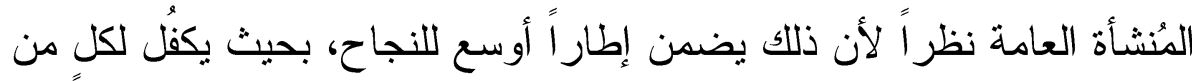

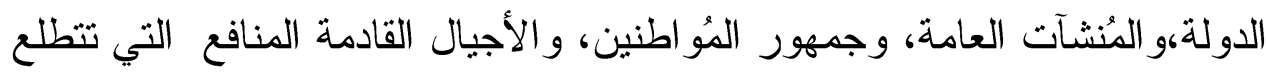
إليها من هذه البر امج • البهاب (9)ينبغي عدم تهاون الدول النامية في مُكافحة التضخم، ومُحاربة الفساد و المحسوبية إلى قد تُصاحب تطبيقات الخصخصة. (10)الإطلاع المُستمر على تجارب تطبيقات الخصخصة في الدول الأخرى

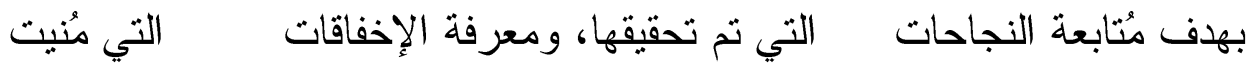

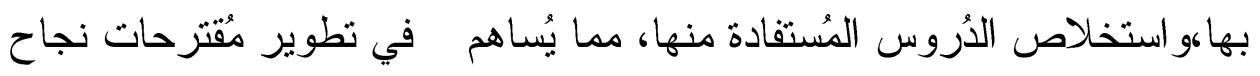

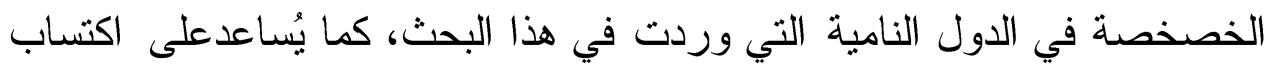

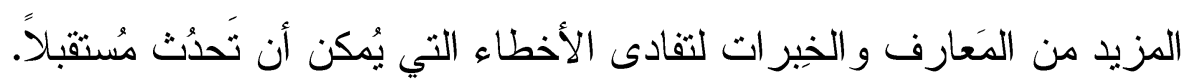




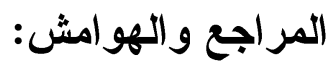

(1)Jerome, A. "Privatization \& Enterprise Performance in Nigeria: Case Study of Some Privatized Enterprises “, Research Paper No. 175 - African Economic Research Consortium, Nairobi,Feb. 2008. (2)Boycko,M., et al, (1996), "A Theory of Privatization", the Economic Journal, 106 (March), 309-319.

(3) Nellis,J., "The World Bank Privatization and Enterprise Reform in Transition Economies: A Retrospective Analysis" - The World Bank, 2001.

(4)Nwoye, I., 2011, "Privatization of Public Enterprises in Nigeria: The Views and Counterviews",globalizacija.com en/e 0062pri.htm.

(5) Young, R., (1991), Privatization in Africa ", Review of African Political Economy No. 51 pp. 50 - 62.

$$
\text { (6) (6) (19) (6صدر سبق ذكره }
$$

(7) Valauskas, E., "A review of Privatization, "INSPEL 33 (1999), pp.1-9 (this paper was presented at the $64^{\text {th }}$ IFLA General Conference, August 16-21, 1998 in Amsterdam).

(8) Shehadi, K., (2002), "Lessons in Privatization", United Nations Development Programme (UNDP).

(9) Gollust, S., et al. "Privatization of Public Services: Organizational Reform Efforts in Public Education \& Pubic Health “, American Journal of Health (2006), Vol .96. No. 10 pp. 1733-1739.

(10)أبو عامرية، فالح (1739-2008) الخصخصة وتأثيراتها الاقتصادية. دار أسامة

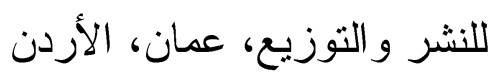

(11) Starr, P., (1988) "The Meaning of Privatization" Yale Law \& Policy Review6 (1988): 641http://www.princeton.edu/starr/meaning.html 


$$
\text { بجلةجامعةأمدرمان الإسلامية (العدد السابعوالعشرونوالثاني عشر الكترونيا) العام 1437هـ 2015م. }
$$

(12) Nellis .J. , \&Kikeri ,S., (1989) , "Public Enterprise Reform Privatization and the World Bank ", World Development, Vol. 17, No.5, pp. 659-672, the World Bank, printed in UK .

(13) Tatahi, M., (2006)"Privatization Performance in Major European Countries since 1980 “. Palgrave Macmillan, Hampshire \& New York.

(14) Wortzel. H., \&Wortzel,L., (1989),"Privatization Not the Only Answer ", World Development Vol. 17, No. 5 pp.633-641.

(15) الفاعوري، رفعت عبدالحلي، (2004م) تجارب عربية في الخصخصة.

$$
\text { المنظمة العربية للتنمية الإدارية، القاهرة، جمهورية مصر العربية. }
$$

(16)Fafaliou, I., \&Donaldson, J.,"The Contribution of Privatization to Welfare", IntAdv Econ Res (2007) 13:461-474

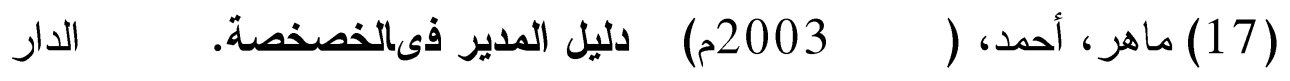

$$
\text { الجامعية،الإسكندرية، جمهورية مصر العربية. }
$$

(18) Savas, E., (2005), pp. 1-17, "Privatization \& Public - Private Partnerships" Adapted From. Savas E., Privatization in the City: Successes، Failures, Lessons,(Washington, DC: CQ Press, 2005), Chapter 1.

$$
\text { (20) (19) مصدر سبق ذكره }
$$

(21)Gomez, E., "Privatization and Public Enterprise Reform in the Asia - Pacificregion"Journal of the Asia Pacific Economy, (1997), 2:2, 178 200.

$$
\text { (23) مصدر سبق ذكره }
$$

(24) Chang, C., (2006) Privatization \& Development: Theory, Policy

\& Evidence. Ashgate Publishing limited, England \& USA.

$$
\text { (26) مصدر سبق ذكره }
$$


د. عبد الله الطيبنموذج استراتيجي للخصخصة الناجحةص:312_ي

$$
\text { (27) (28) مصدر سبق ذكره سبق ذكره }
$$

(30)يلليس، ج، "هل حان الوقت لإعادة التفكير في الخصخصة فيلإقتصادابلتي

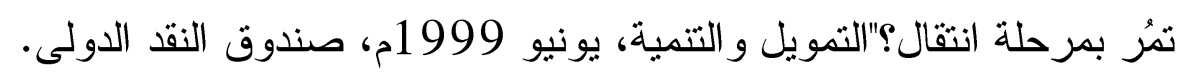
(31) Nellis, J. "Privatization in Developing Countries: A Summary Assessment" Distinguished Lecture Series 24, A Publication of the Egyptian Center forEconomicStudies. December, 2005.

$$
\text { (32) مصدر سبق ذكره }
$$

(33) Roland.,"Privatization...Successes and Failures"Columbia University Press, NewYork (2008), pp.1-198,

http://www.bus.indiana.edu/nagupta/g upta-survey chapter. Pdf 